Anuario Latinoamericano Ciencias Políticas

y Relaciones Internacionales vol. 5, 2017

pp. 253-289

\section{La cooperación de Colombia y México en la lucha contra el narcotráfico: esperanzas y temores asociados con la implementación del modelo colombiano de la seguridad pública en México*}

\section{The cooperation of Colombia and Mexico in the fight against drug trafficking: hopes and fears associated with the implementation of the Colombian model of public safety in Mexico}

\author{
Pawet Trefler $* *$ \\ ESCUELA SUPERIOR ESTATAL DE EUROPA ORIENTAL \\ DE PRZEMYŚL, POLONIA \\ $\triangle$ rektorat@pwsw.pl \\ Raúl Ruiz Canizales $* * *$ \\ UNIVERSIDAD AUTÓNOMA DE QUERÉTARO, MÉXICO \\ $\triangle$ raul.canizales@hotmail.com \\ Benjamín Ortega Guerra ${ }^{* * * *}$ \\ UNIVERSIDAD AUTÓNOMA DE QUERÉTARO, MÉXICO \\ $\triangle$ benorgue_morbus@hotmail.com
}

\section{RESUMEN}

Este artículo ofrece una descripción y una evaluación crítica de la forma y las circunstancias de la cooperación entre Colombia y México en la lucha contra el narcotráfico, así como un análisis de los instrumentos internacionales y diplomáticos que se han utilizado en la implementación de esta relación bilateral. También se

*El presente artículo es producto del proyecto de investigación titulado "La cooperación entre Colombia y México para la seguridad ciudadana en los años 2000-2015”, financiado dentro del marco de la convocatoria del Fondo para el Fortalecimiento de la Investigación UAQ-2015. Número de registro: FDE201603. Agradecemos al FOFIUAQ el financiamiento y apoyo brindado para este proyecto de investigación.

** Doctor en Ciencia Política por la Universidad Jaguelónica. Rector de la Escuela Superior Estatal de Europa Oriental de Przemyśl.

*** Doctor en Derecho por la Universidad Autónoma de Querétaro. Es Profesor investigador de Tiempo Completo (PTC nivel VII), miembro del Sistema Nacional de Investigadores (SNI) del Consejo Nacional de Ciencia y Tecnología (Conacyt).

**** Licenciado en Ciencias Políticas y Administración Pública por la Universidad Autónoma de Querétaro. Maestro en Filosofía Contemporánea Aplicada. 
centra en el papel crucial que los Estados Unidos (EE.UU.) han desempeñado como factor y facilitador de esta relación. Incluye un análisis de los elementos básicos de las medidas actuales de lucha contra el narcotráfico y el fortalecimiento de la seguridad pública para Colombia y México. Una serie de entrevistas con expertos en la materia muestra que hay poco optimismo sobre el futuro de la colaboración entre estos países con respecto a la implementación del modelo colombiano de seguridad pública en México. Se concluye que, en el caso de México, la lucha anterior y efectiva contra la actual corrupción estatal es un elemento esencial. Sin este elemento, los resultados de la Iniciativa Mérida serán mínimos y la sospecha de su éxito tendrá un efecto negativo en la asignación de recursos por parte del gobierno de EE.UU.

PALABRAS CLAVE: Colombia, México, EE.UU., narcotráfico, seguridad, Plan Colombia, Iniciativa Mérida, cooperación Sur-Sur.

\section{ABSTRACT}

This article offers a description and critical evaluation of the form and the circumstances of cooperation between Colombia and Mexico in the fight against drug trafficking as well as an analysis of the international and diplomatic instruments that have been used in the implementation of this bilateral relationship. It focuses also on the crucial role that the US has played as a factor and facilitator of this relationship. It includes an analysis of the basic elements of current measures of combating drug trafficking and the strengthening of public security for Colombia and Mexico. A series of interviews with experts on the subject shows that there is little optimism about the future collaboration between these countries with respect to the implementation of the Colombian model of public security in Mexico. It is concluded that, in the case of Mexico, the previous and somewhat effective fight against current state corruption is an essential element of the strategy. Without this element the results of the Mérida Initiative will be minimal, and the doubt of its success will have a negative effect on the allocation of resources by the US government.

KEYWORDS: Colombia, Mexico, USA, drug trafficking, security, Plan Colombia, Merida Initiative, South-South cooperation.

\section{Introducción}

En los últimos 30 años hemos visto un constante proceso de fortalecimiento de las relaciones diplomáticas entre Colombia y México. Estos países a partir de 2015 son socios estratégicos, ${ }^{1}$ especialmente en dos cuestiones fundamentales: la cooperación económica y la cooperación en el área de seguridad en el contexto del problema de la lucha contra la delincuencia organizada

1 El 8 de mayo de 2015, el presidente de Colombia Juan Manuel Santos realizó una visita de Estado a México. En el marco de la visita se acordó, a través de un memorándum de entendimiento, elevar la relación bilateral al nivel de relación estratégica (Holguín Cuéllar 2015: 33). 
transnacional. Las relaciones de Colombia y México se desarrollan muy bien, especialmente desde la toma de posesión de Felipe Calderón Hinojosa como presidente de México en 2006. Estos países tienen contactos bilaterales regulares al más alto nivel, así como una relación de trabajo eficaz a varios niveles que abarca una amplia gama de campos (Embajada de Colombia 2017). Colombia y México se han acercado el uno al otro en el ámbito internacional, recientemente en el marco de la iniciativa de integración regional la Alianza del Pacífico, así como del Mecanismo de Diálogo y Concertación de Tuxtla, ${ }^{2}$ el Proyecto de Integración y Desarrollo de Mesoamérica (más conocido como el Proyecto Mesoamérica). ${ }^{3}$

Los actuales presidentes de Colombia, Juan Manuel Santos Calderón, y de México, Enrique Peña Nieto, enfatizan su amistad y, en realidad, son amigos y se reúnen regularmente, incluso han declarado que las relaciones entre México y Colombia están mejor que nunca (Presidencia de la República 2015). La confirmación de esto es la primera reunión del Comité Estratégico Colombo-Mexicano prevista en 2017. El Comité fue creado el 8 de mayo del 2015 mediante el "Memorándum de Entendimiento entre la República de Colombia y los Estados Unidos Mexicanos para el Establecimiento de la Relación Estratégica", integrado por empresarios, académicos y otras personalidades, con el objetivo de identificar áreas y sectores para nuevas oportunidades de cooperación (Notigape 2017).

Tanto para México como para Colombia, invariablemente, el principal punto de referencia es EE.UU., que marcó fuertemente la historia de estos dos países latinoamericanos. La turbulenta historia de las relaciones colomboestadounidense y mexicano-estadounidense no altera el hecho de que tanto Colombia como México quieren ser vistos como los más cercanos aliados de EE.UU. Esto se debe principalmente a las oportunidades que ofrece la estrecha

2 El Mecanismo de Diálogo y Concertación de Tuxtla (Mecanismo de Tuxtla) es una iniciativa mexicana para promover el diálogo político, consolidar la paz, la democracia y fomentar la cooperación regional en Centroamérica. Tiene antecedente en la Reunión Cumbre realizada los días 10 y 11 de enero de 1991 en Tuxtla Gutiérrez, Chiapas, en la que participaron los presidentes de Costa Rica, El Salvador, Guatemala, Honduras, México y Nicaragua. Mecanismo que fue creado formalmente durante la "Cumbre Tuxtla Gutiérrez II", celebrada los días 15 y 16 de febrero de 1996, en San José, Costa Rica, en la que fue firmada la "Declaración conjunta de Jefes de Estado y de Gobierno de Centroamérica y México”. A los miembros fundadores -Costa Rica, El Salvador, Guatemala, Honduras, México y Nicaragua- en 1996 se incorporaron Belice y Panamá, y en el 2009, ingresaron Colombia y República Dominicana (SRE 2015).

3 El Proyecto de Integración y Desarrollo de Mesoamérica fue establecido en 2008 por iniciativa de México. Inicialmente se denominó el Plan Puebla-Panamá (PPP). El Proyecto Mesoamérica es un mecanismo de diálogo y coordinación que articula esfuerzos de cooperación, desarrollo e integración entre los países de la región mesoamericana para construir consensos, articular esfuerzos de cooperación y atraer recursos para fortalecer los procesos de integración y desarrollo mesoamericano con el objetivo de mejorar la calidad de vida de los habitantes de Belice, Colombia, Costa Rica, El Salvador, Guatemala, Honduras, México, Nicaragua, Panamá y República Dominicana (AMECID 2016).
La cooperación de Colombia y México en la lucha contra el narcotráfico: Esperanzas y temores asociados con la implementación del modelo colombiano de la seguridad pública en México

Paweł Trefler Raúl Ruiz Canizales Benjamín Ortega Guerra 
cooperación económica con la mayor economía del mundo ${ }^{4}$. Hasta la llegada de Donald Trump a la Casa Blanca, Colombia y México han sido en realidad los aliados estratégicos más importantes de EE.UU. en América Latina.

El objetivo de este artículo no es, sin embargo, un análisis de la historia de las relaciones diplomáticas y económicas entre México y Colombia, con EE.UU. en el fondo, o la presentación del proceso de integración económica de estos países. Más bien se trata de mostrar su cooperación en la lucha contra el tráfico de drogas, cuya razón principal era y sigue siendo una gran demanda de la sociedad estadounidense de la cocaína producida en Colombia, ${ }^{5}$ así como otras drogas exportadas de México a EE.UU. ${ }^{6}$ Sin lugar a dudas, analizando este problema, nos enfrentamos con una relación triangular inseparable, cuya piedra angular es cocaína exportada de Colombia por México a EE.UU. Los estadounidenses son los mayores consumidores de cocaína en el mundo. Los cárteles mexicanos son los principales intermediarios en este negocio. Trasladan cocaína de Colombia a EE.UU., a lo que contribuyeron norteamericanos, reforzando el control en la ruta del Caribe utilizada por los colombianos (Rodríguez Beruff, Cordero 2005). No sólo se trata de cocaína. Hay que tener en cuenta también una larga tradición de la exportación al norte de la marihuana y heroína mexicana, y desde hace poco las drogas sintéticas, principalmente la anfetamina y los derivados de la anfetamina, como el éxtasis o la metanfetamina. Todo esto tiene que ver con una amplia red internacional de fabricantes de narcóticos y narcotraficantes, así como proveedores de productos necesarios para producir los estupefacientes y las personas responsables por el blanqueo de capitales.

En este artículo vamos a tratar de encontrar respuestas a preguntas acerca de ¿por qué y cuáles son los elementos del know-how en el campo de la lucha

4 EE.UU. es el principal socio comercial de ambos países. En 2011, Colombia y EE.UU. firmaron el Tratado de Libre Comercio (el Acuerdo de Promociones Comerciales entre Estados Unidos y Colombia). En el caso de México, un acuerdo similar con EE.UU. y Canadá fue firmado en 1992 - Tratado de Libre Comercio de América del Norte (TLCAN). Cabe mencionar que este tipo de acuerdo desde 1995 conecta también Colombia y México (el Acuerdo de Complementación Económica), al cual pertenecía en los años 1995-2006 Venezuela, formando el Grupo de los Tres, G3. Actualmente la cooperación económica de Colombia y México junto con Chile y Perú se lleva a cabo en el marco de la fundada en 2012 Alianza del Pacífico. Colombia es para México el segundo socio comercial en América Latina y el Caribe, y el primero en la Alianza del Pacífico, mientras que México es el tercer socio comercial de Colombia, después de EE.UU. y China (Noticias Terra 2017).

5 Tras más de una década en descenso, el consumo de cocaína en EE.UU. al parecer está volviendo a crecer. Según la Encuesta Nacional sobre el Uso de Drogas que realiza anualmente el gobierno de EE.UU., entre el 2009 y el 2014 el consumo de cocaína reportado entre mayores de 12 años osciló entre 1,4 y 1,7 millones de personas. Pero en el año 2015 esa cifra saltó a 1,9 millones de personas ( $0,7 \%$ de esta población), un incremento del $23 \%$, si se compara con el dato del 2014 (1,5 millones de personas) y la cifra más alta desde el 2008 (Gómez Maseri 2017).

6 Entre el 90\% y el 94\% de la heroína consumida en EE.UU. proviene de México, donde se espera que los cultivos de opio sigan creciendo en el futuro próximo. El 90\% de cocaína proviene de Colombia (DOS 2017b). 
contra el tráfico de drogas y la construcción de la seguridad pública transferidos de Colombia a México? ¿Cómo se hace esto y qué papel juega en ello EE.UU.? Aunque la transferencia de estas experiencias es un hecho, muchos investigadores siguen preguntando si esto realmente tiene sentido y, si es así, cuál es el contenido que se transfiere durante el entrenamiento, quiénes son los capacitados y capacitadores, así como, cómo medir los efectos del intercambio de experiencias (Arratia Sandoval 2015: 20-21; Kinosian, LindsayPoland, Haugaard 2015; Tickner 2014: 1-2). Es difícil encontrar respuestas a muchas de estas preguntas, principalmente debido a la falta de transparencia en esta área. En principio, se puede confiar sólo en los datos y las declaraciones oficiales y también los artículos de prensa. Los autores de este artículo se encontraron con este problema durante la investigación titulada "La cooperación entre Colombia y México para la seguridad ciudadana en los años 2000-2015"7 realizada en los años 2015-2016.

Uno de los elementos del proyecto antes mencionado fue la encuesta llevada a cabo con el objetivo de conocer la experiencia y opinión de expertos en la cooperación entre México y Colombia en materia de seguridad pública contra el narcotráfico. Dicha encuesta contó con ocho preguntas mixtas realizadas a diez académicos (dos mujeres y ocho hombres). Los resultados se presentarán en la parte final del artículo.

No cabe duda que la transferencia de experiencia siempre puede traer algunos resultados positivos, pero hay que ser crítico y tener en cuenta las circunstancias locales. Por consiguiente, se debe prestar atención a las diferencias significativas en el posicionamiento geopolítico de Colombia y México (especialmente en relación con EE.UU.), su historia y sus diferentes realidades socio-políticas, así como la organización y el modo de actuar de los grupos delictivos organizados de ambos países. Antes de todo, es importante recordar que México no tiene un conflicto interno, pero tiene cárteles que trafican drogas y se están disputando el control de las rutas de tráfico de enervantes (Rosen, Zepeda Martínez 2014: 192) y, además, las soluciones implementadas en la lucha contra el narcotráfico en Colombia no han demostrado ser muy eficaces. La observación de la lucha contra el narcotráfico en otros países es una alerta para evitar los errores cometidos. El problema es que las soluciones aplicadas en Colombia y transferidas, entre otros, a México, son resultantes de los objetivos, medios y métodos de la guerra contra las drogas a la cual los norteamericanos destinan grandes sumas de dinero. ${ }^{8}$ A pesar de la crítica cada vez más fuerte a la idea de guerra antidrogas, los políticos y funcionarios norteamericanos más importantes siguen creyendo que el modelo de la lucha

7 Proyecto registrado y financiado en el marco de la convocatoria del Fondo para el Fortalecimiento de la Investigación UAQ-2015. Número de registro: FDE201603.

8 Según los cálculos oficiales, entre 20 y 25 millones de estadunidenses usa alguna droga ilícita. Los fondos del presupuesto federal asignado a la guerra antidrogas en 2015 alcanzaron más de \$US 25.000 millones. La misma cantidad se gastó en los niveles estatal y local (DPA 2015).
La cooperación de Colombia y México en la lucha contra el narcotráfico: Esperanzas y temores asociados con la implementación del modelo colombiano de la seguridad pública en México

Paweł Trefler

Raúl Ruiz Canizales

Benjamín Ortega Guerra 
contra las drogas, aplicada en la escala más amplia en Colombia, en general funciona bien. Sólo se debe mejorar un poco y poner en práctica en otros países. ${ }^{9}$ La implementación de este modelo significa la militarización de la lucha contra el narcotráfico, lo que resulta muy ventajoso para la industria militar, de defensa y armamentista norteamericana y sus sectores asociados, que gracias al dinero de los contribuyentes estadounidenses, asignado entre otros para el Plan Colombia, la Iniciativa Mérida, la Iniciativa Regional Andina, ${ }^{10}$ la Iniciativa Regional de Seguridad para América Central (CARSI - the Central America Regional Security Initiative), ${ }^{11}$ la Iniciativa de Seguridad de la Cuenca del Caribe (CBSI - the Caribbean Basin Security Initiative), ${ }^{12}$ provee las $\operatorname{armas}^{13}$ y los especialistas para la guerra antinarcos. Esta guerra da también justificaciones o razones para la existencia de muchas de las agencias de seguridad norteamericanas, mientras que la gente común está expuesta a la violencia constante.

En la primera parte del artículo se presenta la génesis de la cooperación entre Colombia y México en la lucha contra el narcotráfico y el intercambio de experiencias en materia de construcción de la seguridad pública. Se acerca también a la breve historia del desarrollo del negocio de la droga en Colombia y México. En la segunda parte se analizan circunstancias, supuestos y efectos del Plan Colombia. Gracias a los enormes recursos financieros y personales designados por EE.UU. para modernizar el equipamiento de las Fuerzas Militares de Colombia y entrenar a sus integrantes, y también a consecuencia de la experiencia en combate contra los guerrilleros, el know-how colombiano en

9 Véase: Stavridis 2015. El presidente del Estado Mayor Conjunto de EE.UU., almirante Mike Mullen, dijo en 2010: „Hay mucho que aprender del éxito que se ha visto aquí en Colombia” (Lustig 2010). Hillary Clinton durante su campaña presidencial en 2016 dijo: "Cuando mi esposo era presidente, como usted recuerda, hubo en Colombia una guerra por parte de narcotraficantes y rebeldes. (...) E hicimos algo llamado Plan Colombia. Ayudamos al gobierno a encontrar el modo de proteger a su país de los narcotraficantes y rebeldes. Esto tomó algunos años, pero ahora es una historia de éxito" (Norman 2016).

${ }^{10}$ La Iniciativa Regional Andina (IRA) fue presentada al Congreso de EE.UU. por el presidente George W. Bush Jr. en abril de 2001 y aprobada poco tiempo después para extender la estrategia antinarcóticos y antiterrorista del Plan Colombia. En marco de esta Iniciativa se asignaron los fondos principalmente a Colombia y mucho menos a Perú, Bolivia, Ecuador, Venezuela, Brasil y Panamá. Esta Iniciativa incluyó recursos para combatir el narcotráfico, fortalecer la democracia y desarrollar la región (véase: Mack 2001).

11 La Iniciativa de Mérida fue anunciada en el otoño de 2007, y originalmente incluyó a Centroamérica dentro de ella, pero en 2010, EE.UU. separó CARSI, que cubre Belice, Costa Rica, El Salvador, Guatemala, Honduras, Nicaragua y Panamá. Los EE.UU. financió CARSI a la cantidad de US\$ 979 millones entre 2008 y 2016 (DOS 2017a).

12 CBSI fue anunciado en abril de 2009. CBSI reúne a miembros de la Comunidad del Caribe (CARICOM) y República Dominicana para colaborar en seguridad regional con EE.UU., que comprometió US\$ 437 millones en financiamiento desde 2010 (DOS 2017d).

13 Según datos del Departamento de Alcohol, Tabaco, Armas de Fuego y Explosivos (ATF Bureau of Alcohol, Tobacco, Firearms and Explosives) 73.684 armas de fuego (alrededor del 70\%) incautadas al crimen organizado en México de 2009 a 2014 provienen de EE.UU. (GAO 2016). 
la guerra antinarco y la contrainsurgencia se convirtió deseable no solo en los países latinoamericanos. En la siguiente parte se trata de la transferencia del know-how colombiano a México en el marco de la Iniciativa Mérida, refiriéndose a las preocupaciones relacionadas a este proceso. Al final se presentan los resultados de la mencionada encuesta que se refiere a las cuestiones planteadas en este artículo.

El artículo se basa en documentos oficiales, informes, artículos científicos y de prensa presentados por los principales expertos en el campo de narcotráfico y seguridad, principalmente de América Latina.

\section{La génesis de la cooperación de Colombia y México en seguridad}

Los inicios de la lucha conjunta de Colombia y México contra el crimen organizado y el narcotráfico se remontan a la segunda mitad de los años 80 del siglo pasado, lo que fue obligado por la actividad de los dos cárteles colombianos -el Cartel de Medellín bajo el liderazgo de Pablo Emilio Escobar Gaviria y fundado en 1976- y el Cartel de Cali -fundado en 1977 y dirigido por los hermanos Gilberto y Miguel Rodríguez Orejuela. Estas organizaciones criminales, ante los intentos de EE.UU. iniciados en 1982 de bloquear la ruta caribeña de traslado de cocaína, empezaron a buscar nuevas rutas por Panamá, otros países centroamericanos y México, y también por mar a lo largo de la costa del Pacífico, por Yucatán y luego a lo largo de la costa del Golfo de México. Por lo tanto, los cárteles colombianos tuvieron que establecer estrechos vínculos con los cárteles mexicanos, que previamente se especializaban en la producción y el traslado de marihuana y heroína a EE.UU.

Aunque el problema del tráfico internacional de estupefacientes tiene sus raíces en el siglo XIX, realmente se empezó a tratar este problema de una manera más decisiva en los años 70 del siglo XX, cuando el presidente de EE.UU. Richard Nixon en su discurso desde la Casa Blanca, el 17 de junio de 1971 (Nixon 1971), anunció el inicio de la guerra contra las drogas y 3 años más tarde fundó la Administración de Cumplimiento de Leyes sobre las Drogas (DEA - Drug Enforcement Administration). ${ }^{14} \mathrm{El}$ siguiente paso, después de que Nixon había proclamado que "el enemigo público número uno de EE.UU. es el abuso de drogas" y "para poder luchar y derrotar este enemigo es necesario llevar a cabo una ofensiva nueva y plena" (Nixon 1971), era cada vez más fuerte la presión ejercida por EE.UU. a México y luego también a Colombia (en consecuencia de la "bonanza cocalera"), para que estos países desplegaran los programas de la lucha contra el narcotráfico y permitieran operar en sus territorios a los agentes de las fuerzas de seguridad norteamericanas respon-

${ }^{14}$ La DEA fue fundada el 1 de julio de 1973 para hacer cumplir la Ley de Sustancias Controladas de 1970 (CSA - Controlled Substances Act).
La cooperación de Colombia y México en la lucha contra el narcotráfico: Esperanzas y temores asociados con la implementación del modelo colombiano de la seguridad pública en México

Paweł Trefler

Raúl Ruiz Canizales

Benjamín Ortega Guerra 
sables por la lucha antinarco. La sanción por falta de la cooperación adecuada por parte de los países productores de drogas iban a ser las sanciones financieras aplicadas sobre la base de los resultados anuales del Proceso de Certificación de las Drogas realizado por EE.UU.

En los años 80 en América operaban dos más grandes cárteles del narcotráfico: en México el Cartel de Guadalajara especializado en la producción y exportación de marihuana y heroína hacia EE.UU., y en Colombia el Cartel de Medellín, que se dedicaba a la producción y el contrabando de cocaína directamente al mismo país. El modus operandi de estas organizaciones criminales se dio en parte por el efecto de la diferente realidad histórica, geopolítica, económica, social y cultural de Colombia y México, lo que contribuyó para que el mayor peso de la guerra contra las drogas en este período fuera transferido de México a Colombia que empezó a ser llamada como el "narcoestado".

En México, desde principios de los años 30 del siglo XX, el poder era ejercido por el Partido Revolucionario Institucional (PRI). El sistema autoritario vigente en este país garantizaba la estabilidad política hasta el año 2000, cuando Vicente Fox Quesada -del Partido Acción Nacional (PAN)- asumió la presidencia. En la época del PRI se constituyó la "paz narca” entre los narcotraficantes y políticos, firmemente arraigada especialmente en los estados y municipios, que consistía en que los criminales, a cambio de sobornos, y a condición de no violar el orden público, podían operar en una forma limitada y discreta, enfocados en la exportación de estupefacientes a EE.UU. El gobierno de México, para calmar a su vecino del norte, llevaba a cabo de vez en cuando las espectaculares operaciones antidrogas, pero por lo general no había bastante determinación para detener el desarrollo de la "narcoindustria", que empezó a traer más y más ingresos no sólo a los criminales, sino también a los políticos y funcionarios públicos corruptos (Grillo 2012; Valdés 2013; Astorga 2015a).

En Colombia, la mayor parte de los políticos también trataron de establecer un sistema similar, pero la situación en algún momento se salió de control. El mayor capo de la droga, Pablo Escobar, quien se consideraba a sí mismo ser más que tan sólo un criminal (él tenía ambiciones políticas), no actuaba discretamente convirtiéndose en una persona pública, lo que no le impedía eliminar brutalmente a los competidores en el negocio, los políticos y periodistas, que señalaban públicamente el problema del creciente poder del mundo criminal y exhortaban a su erradicación, incluso con el apoyo directo de EE.UU. A pesar de que muchos funcionarios eran corruptos, un grupo de políticos con una visión y posicionamiento diferente trataron de combatir a los criminales cuyo poder era cada vez más evidente y comenzó a amenazar al Estado así como la guerrilla (Bowden 2010).

El punto de inflamación con el que se inició la lucha del Estado contra el mundo criminal fue el consentimiento de las autoridades colombianas a la extradición de los ciudadanos colombianos hacia EE.UU., aprobada por la Ley 27 de 1980. Después del asesinato -por orden de Escobar, el 30 de abril de 
1984- del ministro de Justicia de Colombia, Rodrigo Lara Bonilla -el principal promotor de la ley de extradición suspendida en el año 1982 por el presidente Belisario Betancur Cuaras-, el gobierno colombiano reconoció los cárteles de la droga como una amenaza para la seguridad nacional, y se inclinaba cada vez más a aceptar la ayuda de los norteamericanos en el combate con los narcotraficantes. Esto provocó una reacción furiosa de Escobar, quien comenzó una guerra brutal contra el Estado. En circulación entraron entonces las nuevas palabras como por ejemplo: el "narcoterrorismo" y la "narcoguerrilla". ${ }^{15}$

El presidente de EE.UU., Ronald Reagan, el 8 de abril de 1986, firmó la National Security Decision Directive (NSDD) no. 221 "Narcóticos y Seguridad Nacional", en la que por primera vez reconoció el tráfico de drogas como una amenaza a la seguridad nacional. Un año más tarde, el presidente de México, Miguel de la Madrid, hizo lo mismo. En 1996, el presidente de México Ernesto Zedillo Ponce de León declaró el tráfico como la mayor amenaza a la seguridad nacional de México, la cual debía ser combatida por las Fuerzas Armadas. Felipe Calderón Hinojosa pasó de las palabras a los hechos y el 11 de diciembre de 2006 ordenó el comienzo del operativo militar contra el crimen organizado en el estado de Michoacán. En la guerra contra el narcotráfico el gobierno de Calderón desplegó hasta 45.000 tropas federales, complementadas con efectivos de la Policía Federal (Haugaard, Isacson, Johnson 2001: 1). Se calcula que desde el inicio esta guerra ha provocado 150.000 muertos y unos 28.000 desaparecidos (Pardo Veiras 2016).

Al revisar algunos hechos sobre la delincuencia organizada en América Latina, vemos que aunque los primeros contactos de los narcotraficantes colombianos y mexicanos se remontan a finales de los años 70 del siglo XX, esta cooperación comenzó a desarrollarse dinámicamente a mediados de los años 80, cuando los traficantes mexicanos de marihuana y heroína empezaron a la orden de sus pares colombianos a trasladar cocaína a EE.UU. Un papel clave en la asociación de los cárteles de Medellín y Guadalajara jugó el capo colombiano José Gonzalo Rodríguez Gacha conocido comúnmente como "El Mexicano", quien a finales de los años 70 se puso en contacto con el capo mexicano, uno de los fundadores del Cártel de Guadalajara, Miguel Ángel Félix Gallardo "El Padrino".

La conexión criminal entre Colombia y México no fue afectada por la detención y encarcelamiento de Gallardo (el 8 de abril de 1989), o la muerte de Rodríguez Gacha (el 15 de diciembre de 1989) ni por la matanza de Escobar (el 2 de diciembre de 1993) por la unidad de operaciones especiales de la Policía Nacional de Colombia (el Bloque de Búsqueda) con el apoyo activo de los servicios de seguridad de EE.UU., los cuales operaban en Colombia. Al contrario, emergió el nuevo rey del oro blanco, el mexicano Amado Carillo Fuentes, conocido como "El Señor de los Cielos", el capo del Cartel de Juárez, quien se

${ }^{15}$ El encargado de propagar un término que enlaza los dos fenómenos que más han conmovido a Colombia fue el embajador de EE.UU. en Colombia Lewis Tumbs.
La cooperación de Colombia y México en la lucha contra el narcotráfico: Esperanzas y temores asociados con la implementación del modelo colombiano de la seguridad pública en México

Paweł Trefler

Raúl Ruiz Canizales

Benjamín Ortega Guerra 
especializó en la exportación de cocaína por vía aérea de Colombia por México hacia EE.UU. La actividad similar desde el principio de su funcionamiento caracterizó también al Cartel de Sinaloa, heredero del Cartel de Guadalajara y dirigido por Joaquín Archivaldo "El Chapo" Guzmán Loera (extraditado a EE.UU el 19 de enero de 2017) y otros cárteles mexicanos. Después de la caída del Cartel de Medellín las cosas han cambiado. ${ }^{16}$ Los colombianos perdieron la mayor parte de las ganancias de cocaína a favor de los cárteles mexicanos; aquellos se concentraron en la producción, lo que requería incremento de los cultivos de coca en Colombia. A su vez, los cárteles mexicanos se han convertido en los subcontratistas en las organizaciones criminales más poderosas del mundo, de lo que obtienen beneficios del mercadeo de cocaína como su principal proveedor hacia EE.UU. ${ }^{17}$ Debido al hecho de que crecía constantemente la competencia por las rutas de tráfico de drogas hacia EE.UU., mientras que México experimentaba una grave crisis política e institucional, los cárteles mexicanos comenzaron a operar de modo cada vez más abierto y brutal. En las calles apareció una violencia sin precedentes que comenzó a tocar a los ciudadanos comunes. En algunas partes de México la gente perdió completamente su sentido de seguridad. Las muertes en los tiroteos, las extorsiones, los secuestros y los desplazados internos se convirtieron en los fenómenos cada vez más comunes. Esta intensidad de la actividad criminal no podía ser ignorada por las autoridades. El firme intento de restablecer el orden público podría llevar los beneficios políticos considerables. Esto es lo que llevó al nuevo presidente de México, Felipe Calderón Hinojosa, elegido en circunstancias muy controvertidas, ${ }^{18}$ a declarar la guerra contra el narcotráfico (Astorga 2015). Por su parte, EE.UU. anunció su ayuda en esta guerra, como antes en el caso de Colombia. Su apoyo a México también lo ofreció Colombia, que ya tenía mucha experiencia en este tipo de guerra.

Los vínculos crecientes entre el inframundo criminal colombiano y mexicano hizo necesaria la intensificación de los contactos intergubernamentales

${ }_{16}$ Según estimaciones del Instituto de Estudios para el Desarrollo y la Paz (INDEPAZ), en los años 80 los cárteles colombianos se quedaban con el 90\% de las ganancias del negocio al mayoreo de cocaína (lo cual excluye su venta al menudeo en EE.UU.) y hoy ese porcentaje acaba en manos de los cárteles mexicanos (Croda 2015).

17 El Centro de Estudios sobre Seguridad y Drogas de la Universidad de los Andes en Bogotá (CESED) calcula que producir un kilogramo de cocaína en las selvas colombianas cuesta unos US\$ 2.000. Esa droga, puesta en un puerto de Colombia por las bandas criminales (bacrim) locales, alcanza un valor de US\$3.500. Los cárteles mexicanos la compran a ese precio, que se eleva a US\$15.000 al llegar a México y a unos US\$35.000 cuando cruza la frontera de EE.UU. De esta manera, los mexicanos se quedan con US $\$ 31.500$ por cada kilogramo de cocaína que logran ingresar al mercado estadunidense, el 90\% del total, mientras que los colombianos -los productores de hoja de coca, quienes la transforman en cocaína y las bacrim que financian el proceso y acopian la droga- reciben US\$3.500, el 10\% (Croda 2015).

18 El rival de Calderón en las elecciones presidenciales, el político del Partido de la Revolución Democrática (PRD) Andrés Manuel López Obrador, calificó las elecciones de fraude y denunció muchas irregularidades. La diferencia de votos entre los candidatos era tan sólo de 0,1\%. 
entre Colombia y México. Los inicios del acercamiento en las relaciones diplomáticas tuvieron lugar en los años 80 del siglo XX, cuando Colombia y México iniciaron una acción concertada por la paz en Centroamérica; para ello establecieron en el año 1983 el Grupo Contadora, al cual se sumó Venezuela y Panamá. Gracias al establecimiento de los contactos directos por los presidentes de Colombia, Belisario Betancur Cuaras, y el presidente de México, Miguel de la Madrid, en los años 80 estos países ampliaron la agenda de las relaciones mutuas y dieron los primeros pasos conjuntos para combatir el narcotráfico. A continuación, las autoridades mexicanas, que han adquirido experiencia en la mediación para poner fin a las guerras civiles en El Salvador y Guatemala, intentaron mediar en el conflicto armado en Colombia, organizando en los años 1990-1991 en Tlaxcala las conversaciones de paz entre los representantes del gobierno de Colombia y los guerrilleros de las Fuerzas Armadas Revolucionarias de Colombia (FARC), el Ejército de Liberación Nacional (ELN) y el Ejército Popular de Liberación (EPL). Sin embargo, estas mediaciones no trajeron los resultados esperados. Al mismo tiempo, estos países desarrollaban rápidamente la cooperación económica, que llevó a la creación del antes mencionado Grupo de los Tres (G3).

La formalización de la cooperación en seguridad entre Colombia y México se produjo cuando Vicente Fox Quesada era el presidente de México, y quien -no por casualidad- escogió Bogotá como el destino de su primera visita de Estado. Durante la reunión con el presidente de Colombia, Andrés Pastrana Arango, que tuvo lugar el 5 y 6 de abril de 2001, Fox buscaba el apoyo diplomático para suprimir el proceso de certificación hecho por EE.UU. ${ }^{19}$ Fox sostuvo que la lucha contra el narcotráfico no puede basarse en las soluciones unilaterales, pero requiere una amplia cooperación internacional, porque es un fenómeno internacional que existe principalmente debido a la demanda de drogas en los países desarrollados y, además, es asociado a otros tipos del crimen organizado transnacional, como, por ejemplo, el lavado de dinero (Buscaglia 2015). En este sentido, Vicente Fox declaró que "La calificación unilateral que hace EE.UU. no contribuye en nada, ni a la reducción del consumo de drogas ni al combate del crimen organizado; sí lo es, es un procedimiento que irrita y de alguna manera ofende a nuestras naciones" (Venegas 2011). Además, el entonces presidente de México expresó la opinión de que EE.UU. debe intensificar los programas de prevención de drogas entre sus ciudadanos. Por lo tanto, propuso a Pastrana la firma de la "Declaración sobre seguridad y justicia”, mediante la cual el 6 de abril de 2001 se formó el Grupo de Alto Nivel de Seguridad y Justicia (GANSJ), donde participan el Ministerio de Defensa colombiano y la Secretaría de la Defensa Nacional mexicana, así como las

19 Colombia durante el gobierno del presidente Ernesto Samper Pizano no era certificada por EE.UU. (Tokatlian 1998). Samper fue acusado de recibir financiación del narcotráfico para su campaña presidencial. EE.UU. le retiró la visa de entrada. Este periodo era llamado "narcodemocracia”.
La cooperación de Colombia y México en la lucha contra el narcotráfico: Esperanzas y temores asociados con la implementación del modelo colombiano de la seguridad pública en México

Paweł Trefler

Raúl Ruiz Canizales

Benjamín Ortega Guerra 
dependencias encargadas del combate de las drogas ilegales en ambos países (Venegas 2011) ${ }^{20}$. El principal objetivo del GANSJ es "servir de eje impulsor de las acciones que desarrollen las autoridades competentes mediante la coordinación de acciones de inteligencia, el intercambio de informaciones y experiencias, así como la cooperación judicial, con el fin de identificar esquemas que permitan desplegar esfuerzos coordinados para combatir el narcotráfico, el desvío de precursores químicos, el contrabando, el lavado de dinero, el tráfico de armas y las distintas formas del crimen organizado, a fin de proporcionar seguridad a ambos países.” (Cámara de Senadores 2013)

Antes de crear el GANSJ, Colombia y México cooperaban en un nivel inferior en el marco del Comité Bilateral de Cooperación contra el Tráfico de Estupefacientes y Sustancias Sicotrópicas creado por el "Acuerdo de cooperación en materia de lucha contra el tráfico ilícito de estupefacientes y sustancias psicotrópicas", suscrito el 17 de enero de $1997 .{ }^{21}$

A cambio del apoyo de Colombia en la lucha contra el narcotráfico, Fox ofreció su ayuda en el diálogo entre el gobierno colombiano y los dirigentes guerrilleros del ELN a través del Grupo de Países Amigos y Facilitadores del Proceso de Paz en Colombia, pero cuando el equipo de los negociadores mexicanos ya había sido formado, en el último momento los insurgentes se negaron a negociar (Súdarev 2013: 8-9). La cuestión de poner fin a la guerra civil en Colombia era muy importante en la lucha contra el narcotráfico, porque las dos guerrillas más importantes del país, las FARC y el ELN estaban fuertemente involucradas en el narcotráfico, al igual que los grupos paramilitares, también denominados autodefensas, con el mayor de ellos Autodefensas Unidas de Colombia (AUC) con la participación de ricos hacendados, colonos, campesinos y pequeños industriales unidos para defenderse de las agresiones guerrilleras.

${ }^{20}$ Este mecanismo está conformado por 5 ejes temáticos: Diálogo político; Cooperación en la lucha contra la delincuencia organizada; Terrorismo y grupos armados ilegales; Procuración de justicia y cooperación en materia judicial, y problema mundial de las drogas. Los participantes por la parte de México son: la Secretaría Técnica del Consejo de Seguridad Nacional de la Presidencia de la República (CSN); Secretaría de Relaciones Exteriores (SRE); Procuraduría General de la República (PGR); Centro de Investigación y Seguridad Nacional (CISEN); Secretaría de Seguridad Pública (SSP); Secretaría de la Defensa Nacional (SEDENA); Secretaría de Marina (SEMAR); Secretaría de Hacienda y Crédito Público (SHCP); Unidad de Inteligencia Financiera (UIF). De parte de Colombia: Ministerio del Interior y de Justicia: Ministerio de Defensa Nacional; Fuerzas Militares de Colombia (FFMM); Policía Nacional de Colombia (PNC); Fiscalía General de la Nación (FGN); Dirección Nacional de Estupefacientes (DNE); Fondo Nacional de Estupefacientes (FNE): Agencia Presidencial para la Acción Social y la Cooperación Internacional (APC-Colombia); Superintendencia de Vigilancia y Seguridad Privada (SVSP); Departamento Administrativo de Seguridad (DAS); Ministerio de Relaciones Exteriores (Cámara de Senadores 2013).

${ }^{21}$ Por parte de México las autoridades competentes son la Secretaría de Relaciones Exteriores (SRE) y la Procuraduría General de la República (PGR). Por parte de Colombia las autoridades competentes son el Ministerio de Relaciones Exteriores y el Ministerio de Justicia y del Derecho. El Comité tiene como función principal la de formular por consenso de las autoridades competentes de ambas partes, recomendaciones a sus gobiernos respecto a la manera más eficaz en que puedan prestarse cooperación (Acuerdo 1997). 


\section{Plan Colombia}

La asociación de los problemas de guerrilla y narcotráfico desde los años 80 , movilizaba a los norteamericanos para monitorear la situación en Colombia y fue un impulso para lanzar el Plan Colombia financiado por EE.UU. ${ }^{22}$ De hecho FARC, ELN y AUC, después de la caída de los cárteles de Medellín y Cali, eran las más grandes organizaciones que se ocupaban de narcotráfico en Colombia. Además, en los años 90 operaba el más grande Cartel del Norte del Valle y también docenas de "baby" cárteles o "cartelitos" colectivamente llamados bandas criminales emergentes (bacrim). ${ }^{23}$

Durante la campaña presidencial de 1998, Andrés Pastrana Arango proclamaba la necesidad de terminar la guerra civil que desde 1948 arruinaba a Colombia. Con este fin, se decidió a buscar la ayuda de EE.UU. y Europa, de los que esperaba un apoyo financiero para la reconstrucción de la economía colombiana. Señaló Pastrana que "Los países desarrollados deben ayudarnos a ejecutar una especie de Plan Marshall para Colombia, que nos permita desarrollar grandes inversiones en el campo social, en el agropecuario y en la infraestructura regional" (Cruz Cruz 2009: 341). El camino hacia la paz llegaría a través de negociaciones de paz con las guerrillas, a las cuales las FARC y el ELN declararon su disposición durante la campaña presidencial, así como a través de recuperación económica, reconstrucción del país y establecimiento del control total sobre todo el territorio colombiano. Pastrana escribió el "Plan Colombia para la Paz" que se enfocó en el proceso de paz, economía y desarrollo y menos en la guerra contra las drogas. Este Plan implicaba asistencia de muchos países (multilateralismo) ${ }^{24}$ ante los problemas derivados del narcotráfico, violencia y crimen organizado (Rosen, Zepeda Martínez 2016: 70). Estos problemas fueron presentados por el gobierno colombiano como una "amenaza" para estabilidad y seguridad hemisférica en la que Colombia era incapaz de enfrentar sin el concurso de EE.UU (Tickner 2007: 106). Sin embargo, cabe señalar que para Pastrana la prioridad del Plan Colombia nunca fue el narcotráfico. Pensaba que lo más importante para su país era el desarrollo económico (Rosen, Zepeda Mar-

${ }^{22}$ Hay que tener en cuenta que durante la década de los años 90, EE.UU. destinó alrededor de \$US 1.000 millones en Colombia a la guerra contra las drogas. Sin embargo, durante esa década Colombia continuó produciendo grandes cantidades de hoja de coca. Por ejemplo, entre 1989 y 1998 la producción de coca se disparó de 33.900 toneladas a 81.400 toneladas, lo que supone un incremento del $140 \%$ en dicho periodo (Bagley 2001).

${ }^{23}$ A partir de mayo de 2016, las bandas criminales (bacrim) pasan a ser llamadas por el gobierno colombiano como grupos armados organizados (GAO) mediante la Directiva 015 del Ministerio de Defensa Nacional, dando facultades a las Fuerzas Militares para combatir estos grupos como si fueran insurgentes, incluyendo bombardeos a campamentos de estas organizaciones (Webinfomil 2016).

${ }^{24} \mathrm{Al}$ inicio circulaban tres versiones del Plan Colombia: la colombiana, la estadounidense y la europea. La versión estadounidense y colombiana eran similares, únicamente cambia el orden de los temas del Plan (Cruz Cruz 2009: 341). Véase: Tokatlian 2011.
La cooperación de Colombia y México en la lucha contra el narcotráfico: Esperanzas y temores asociados con la implementación del modelo colombiano de la seguridad pública en México

Paweł Trefler Raúl Ruiz Canizales Benjamín Ortega Guerra 
tínez 2014: 186). Igualmente importante era encontrar solución al conflicto interno de Colombia.

La Ley 508 del 29 de julio de 1999 aprobó según el mandato constitucional el Plan Nacional de Desarrollo “Cambio para Construir la Paz 1999-2002”. Pastrana viajó a EE.UU. en septiembre de 1998, donde, tras cambiarle el nombre al proyecto, presentó lo que desde entonces se ha conocido como Plan Colombia (Sánchez Cobaleda 2011: 17) y entonces empezaron las negociaciones sobre la versión final del Plan, durante las cuales resultó que el único modo de conseguir el apoyo político necesario para obtener recursos significativos de EE.UU. era presentando la propuesta del Plan Colombia como una medida esencialmente antidroga (Sánchez Cobaleda 2011: 19). Esto se debió al hecho de que Bill Clinton reconoció que EE.UU. no podían intervenir en el conflicto interno de Colombia porque no querían que se repitiera una situación como la de Vietnam (Rosen, Zepeda Martínez 2016: 79). Finalmente la estrategia del Plan Colombia de Pastrana fue reorientada en Washington oficialmente hacia el combate a las drogas, pero en realidad este Plan "fue una estrategia para combatir a las guerrillas de las FARC” (Benítez Manaut 2014: 52). El principal supuesto del Plan Colombia era aceptar de manera oficial los vínculos entre narcotráfico y guerrilla, y "con base en esa idea se consideró que la lucha contra el narcotráfico podría conducir al debilitamiento de los grupos armados ilegales, y viceversa” (Carvajal, Pardo 2002: 192). La versión final del Plan Colombia fue anunciada el 11 de enero de 2000 por el presidente de EE.UU., Bill Clinton. La asistencia estadounidense al Plan Colombia fue convertida en la Ley S1758 (Alianza Act) en julio de 2000 y contemplaba un paquete de ayuda inicial por US \$ 1.300 millones (Pabón Ayala, Ortega Gómez 2009: 255). Desde ese año hasta 2002, EE.UU. ha provisto a Colombia con US \$ 7.500 millones en asistencia militar y no militar. Bajo la supervisión general y la dirección de la Oficina de Políticas Nacionales para el Control de Drogas de la Casa Blanca (ONDCP - White House Office of National Drug Control Policy), los Departamentos de Estado y de Defensa han proporcionado al Ejército Colombiano y a la Policía Nacional de Colombia -la cual forma un cuerpo militarizado y desde 1953 está adscrita al Ministerio de Defensa formando parte de la Fuerza Pública de Colombia- la asistencia requerida para la lucha antinarcóticos y para lograr los objetivos de seguridad. El Departamento de Estado centró sus esfuerzos en los 5 programas principales de aviación para el Ejército, las Fuerzas Aéreas y la Policía Nacional de Colombia. La Agencia Estadounidense para el Desarrollo Internacional (USAID - U.S. Agency for International Development), el Departamento de Justicia y el Departamento de Estado proveyeron también asistencia no militar en los programas de desarrollo alternativo, ayuda a las personas desplazadas internamente, a la desmovilización de los grupos armados y en los esfuerzos para conseguir reformas judiciales (Sánchez Cobaleda 2011: 8).

Con los recursos del Plan Colombia este país se convirtió en el tercer país del mundo que en aquel tiempo recibía más ayuda militar estadounidense, después de Israel y Egipto. Según datos de Security Assistance Monitor, de los casi 
US\$10.000 millones que EE.UU. asignó al Plan Colombia entre los años fiscales 2000 y 2015, casi US\$7.000 millones estuvieron dirigidos a entrenar, ayudar, instruir y equipar fuertemente al ejército y la policía del país (Kinosian, Lindsay-Poland, Haugaard 2015), y sólo US\$3.000 millones para programas de desarrollo social (Arratia Sandoval 2015: 6-7). Colombia aportó adicionalmente en los años 2000-2016 US\$14.000 millones del presupuesto nacional (El Tiempo 2016). Las Fuerzas Militares de Colombia junto con la Policía Nacional de Colombia (la cual forma un cuerpo militarizado) pasaron de 145.000 efectivos en 2000 a 236.000 en 2008 y 450.000 en 2015. El Plan Colombia también le permitió oficialmente a EE.UU. la presencia permanente de un máximo de 500 militares y 400 contratistas de la Secretaría de Defensa, ${ }^{25}$ el acceso a las instalaciones militares colombianas y el uso de los radares colombianos para las labores de inteligencia de ese país. Por estas razones Arlene B. Tickner identificó el Plan Colombia como "intervención por invitación" que "combinó la aceptación de la primacía política, económica y militar de los EE.UU. - un rasgo histórico de la política exterior de Colombia-, la convocatoria a que el país del norte tuviera una fuerte presencia en Colombia, y la enajenación de la autonomía del Estado y de su control sobre los procesos de toma de decisiones respecto de la lucha antidrogas y antiterrorista”. (Tickner 2007: 105-106)

El Plan Colombia tenía principalmente tres componentes: la erradicación forzosa vía fumigación; la reingeniería de las Fuerzas Militares y la Policía Nacional de Colombia, particularmente de los sectores que se involucran en la lucha contra el narcotráfico; la política social, es decir, una política de desarrollo institucional local (Pabón Ayala, Ortega Gómez 2009: 251). La ayuda de EE.UU. incluyó la entrega de unos 90 helicópteros, la fumigación de 1,29 millones de hectáreas de territorio colombiano con herbicidas, y el entrenamiento de más de 70.000 efectivos de La Fuerza Pública de Colombia (Haugaard, Isacson, Johnson 2001: 7).

Con la llegada al gobierno del presidente Álvaro Uribe Vélez, se vinculó el Plan Colombia con su "Política de Defensa y Seguridad Democrática" que identificó 5 amenazas y 5 objetivos estratégicos. Entre las amenazas eran: el terrorismo, el negocio de las drogas ilícitas, las finanzas ilícitas, el tráfico de armas, municiones y explosivos, el secuestro y la extorsión, el homicidio. Entre los objetivos estratégicos se destacó lo siguiente: consolidación del control estatal del territorio, protección de la población, eliminación del negocio de las drogas ilícitas en Colombia, mantenimiento de una capacidad disuasiva, eficiencia, transparencia y rendición

${ }^{25}$ Lo que sucede a lo largo de la implementación del Plan, es una mayor presencia numérica a lo autorizado por el Congreso norteamericano, que demuestra una constante presencia de los norteamericanos en Colombia. Puede decirse, por ejemplo, que para el año 2004 se contaba en Colombia con casi 2.000 estadounidenses en misión oficial (1.200 vinculados a la Embajada de EE.UU., 364 civiles contratados en proyectos del Plan Colombia, y 323 militares en labores de entrenamiento y asesoría), lo que entonces constituía la misión diplomática norteamericana más grande del mundo, después de la en Bagdad (VV. AA. 2004, citado por: Pabón Ayala, Ortega Gómez 2009: 255-256).
La cooperación de Colombia y México en la lucha contra el narcotráfico: Esperanzas y temores asociados con la implementación del modelo colombiano de la seguridad pública en México

Paweł Trefler Raúl Ruiz Canizales Benjamín Ortega Guerra 
de cuentas. Para realizar estos objetivos se decidió fortalecer el sistema judicial, las Fuerzas Militares, la Policía Nacional de Colombia, la inteligencia y las finanzas del Estado. Entre las muchas actividades que se asociaron con la implementación de esta política, fue también el fortalecimiento de la cooperación internacional (PSD 2003). Gracias a la ayuda de EE.UU. Uribe pudo embarcar en 2003 en el departamento de Cundinamarca y después también en los departamentos del Meta, Caquetá, Putumayo y Guaviare el Plan Patriota -la mayor ofensiva militar emprendida contra la guerrilla en la historia de Colombia. ${ }^{26}$

Como resultado del Plan Colombia, originalmente programado para 6 años, la situación de seguridad en Colombia mejoró durante el segundo mandato del gobierno del presidente Uribe (2006-2010), lo que es continuado durante el actual gobierno de Juan Manuel Santos. El Estado ha logrado un mayor control sobre el campo, miles de paramilitares se han desmovilizado, las guerrillas sufrieron muchas derrotas, y un gran número de rebeldes se han rendido voluntariamente, circunstancia que abrió un camino hacia la paz. Los indicadores claves de violencia, incluyendo secuestros, homicidios, desapariciones y desplazamientos forzados, también han disminuido (Tickner 2014: 2). Al final del mandato de Uribe, las tasas de mortalidad de civiles relacionadas con la guerra bajaron a la mitad. Colombia comenzaba a disfrutar de un renacimiento económico hecho posible por una mayor inversión extranjera y el regreso de muchos empresarios y otros líderes económicos que habían huido del país. Sin embargo, los críticos del Plan Colombia señalan que a pesar de que la seguridad ha mejorado y la violencia ha disminuido (en parte gracias a las negociaciones sobre el desarme con las AUC que llevó Uribe ${ }^{27}$ ), el combate a la producción y tráfico de drogas ha sido un fracaso. Colombia continúa siendo el primer país productor de coca y cocaína a nivel mundial. El área de cultivo de coca en 2007 fue casi el mismo que en 2002, luego disminuyó al nivel mínimo en 2012, para crecer de nuevo en los últimos años (UNODC 2016: 17). Aún más, el cultivo y producción de drogas no sólo persistió en Colombia, sino que se desarrolló en países circunvecinos como Perú y Bolivia.

La segunda cuestión planteada por los críticos del Plan Colombia son los graves abusos a los derechos humanos cometidos por las fuerzas de seguridad colombianas. Cabe mencionar que: "El Presidente Uribe defendió a los militares

${ }^{26}$ El Plan Patriota fue una campaña militar de las Fuerzas Militares de la Policía Nacional de Colombia que inicialmente buscaba recuperar las zonas urbanas y las vías de comunicación contra la influencia ejercida por las FARC y el ELN, y en la segunda fase desarticular las estructuras de las FARC en zonas rurales.

27 Las AUC evolucionaron rápidamente, pasando de milicia de protección de hacendados ricos a ser una organización paramilitar derechista implicada en el narcotráfico. Llegaron a tener unos 30.000 hombres en armas. Algunos miembros del gobierno y las Fuerzas Militares aportaron su apoyo. Con la llegada al poder de Álvaro Uribe se inicia la desmovilización y desarme de 34 bloques de las AUC. Casi 30 líderes de las AUC fueron extraditados a EE.UU. para hacer frente a acusaciones por tráfico de drogas, pero otros ingresaron a las bacrim o a los nuevos grupos paramilitares (Haugaard, Isacson, Johnson 2001: 9). 
ante cualquier crítica. El discurso del presidente tachó de simpatizantes de las guerrillas a todos aquellos que denunciaran los abusos a los derechos humanos por parte de militares -lo cual puso en peligro a defensores de los derechos humanos, periodistas y políticos opositores" (Haugaard, Isacson, Johnson 2001: 8). El escándalo más notorio de la falta de una adecuada supervisión de la actividad de las Fuerzas Armadas era el caso de los "falsos positivos" ${ }^{28}$ y la cooperación de los militares con los paramilitares (HRW 2001). En conclusión, podemos decir que Uribe ha logrado fortalecer la capacidad del Estado, pero a costo de ignorar los derechos humanos, aunque al principio él mismo declaró que: "La Seguridad Democrática es lo que se requiere para garantizar la protección de los ciudadanos. Que el Estado proteja a todos por igual y sin distinción, para que todos los colombianos puedan disfrutar de sus derechos." (PSD 2003)

Desde el principio, el tema de violaciones de los derechos humanos era una de las principales quejas de los críticos del trasplante del modelo militarizado de combate al narcotráfico a México, que se implementó en Colombia. Los críticos de este modelo ponen atención a la militarización de la sociedad y lo que esto implica en el debilitamiento de las instituciones democráticas y las restricciones de los derechos humanos. Por otra parte, esto lleva al fortalecimiento del poder ejecutivo sin contrapesos y transparencia, lo que merma poderes a los otros niveles de gobierno, y en consecuencia puede causar severos retrasos en una transición a la democracia (Carlsen 2007). Además, la aplicación de este modelo bajo la presión de EE.UU. constituye una clara amenaza a la soberanía nacional.

\section{La exportación de know-how colombiano en cuanto a contrainsurgencia y lucha contra el narcotráfico a México (Iniciativa Mérida)}

Desde mediados de 2000 comenzó a crecer la demanda de know-how colombiano en cuanto a contrainsurgencia y lucha contra el narcotráfico ${ }^{29}$. Las solicitudes externas para la cooperación colombiana en materia de seguridad

${ }^{28}$ Las Fuerzas Militares colombianas han sido denunciadas por quebrantar los derechos humanos, incluyendo 3.700 supuestas ejecuciones extrajudiciales, también conocidas como "falsos positivos" (una práctica que consiste en reportar como bajas a civiles haciéndolos pasar como combatientes enemigos), la mayor parte de las cuales ocurrieron entre 2002 y 2008 . Según Human Rights Watch, más de 800 miembros del ejército (activos o en retiro) han sido condenados como parte del escándalo de los falsos positivos (Arratia Sandoval 2015: 26).

29 La Fuerza Pública de Colombia transfiere su experiencia desde 1989 cuando empezó a entrenar a los policías de todo el mundo -también de México- en el marco de su programa de lucha contra las drogas, dirigido por el Comando Jungla de la Policía Nacional de Colombia. Desde 1989 el Comando Jungla ha entrenado a cerca de 1.600 policías de países como Perú, Bolivia, Chile, Argentina, Uruguay, Honduras, Costa Rica, Panamá, Brasil, Argentina, Afganistán y México (Marino García 2015).
La cooperación de Colombia y México en la lucha contra el narcotráfico: Esperanzas y temores asociados con la implementación del modelo colombiano de la seguridad pública en México

Paweł Trefler Raúl Ruiz Canizales Benjamín Ortega Guerra 
eran tratadas de manera ad hoc y poco sistemática (Arratia Sandoval 2015: 11). Lo mismo era con la cooperación entre Colombia y México en materia de seguridad, como lo demuestra el hecho de que durante el sexenio presidencial de Fox el GANSJ tuvo poca actividad. Las dos reuniones del mecanismo tuvieron lugar en 2001 y 2003, respectivamente.

La emulación práctica y concreta del modelo colombiano en México despegó bajo el mandato del presidente Felipe Calderón Hinojosa, como consecuencia de su declaración de guerra contra las drogas, que realmente replicó el modelo colombiano para hacer frente al problema. Calderón obtuvo un apoyo del presidente de EE.UU. George W. Bush Jr., quien el 30 de junio de 2008 después de la negociación rodeada de gran secrecía -que había comenzado el 11 de enero de 2007 con la reunión en Mérida entre los presidentes Bush y Calderón y el procurador de EE.UU. Alberto González y de México, Eduardo Medina Mora- quien firmó la ley que avaló la transferencia de recursos para la Iniciativa Mérida -un paquete de asistencia militar de US \$ 1.600 millones (US \$ 1.400 millones para México) para un periodo de tres años, de lo cual el $62,59 \%$ fue asignado para la lucha contra las drogas, antiterrosimo y seguridad fronteriza (principalmente la compra de equipo, incluyendo entre otros: 8 helicópteros Bell 412, 3 helicópteros UH-60 Black Hawk, 4 Aviones CASA 235 (Benítez Manaut, Rodríguez Luna 2009: 50-54); el 22,37\% para la seguridad pública y aplicación de la ley; y el 15,04\% para la creación de instituciones y Estado de Derecho (Olson 2017). En el 2010 la Iniciativa Mérida fue extendida. Hasta ahora bajo la Iniciativa Mérida EE.UU. se ha proporcionado a México US \$ 2.500 millones (DOS 2017c), no obstante, esa cantidad de dinero es realmente muy pequeña comparada con US \$94.000 millones gastado en el mismo periodo del presupuesto de México para la mejora de seguridad (Ribando Seelke, Finklea 2017: 1).

La Iniciativa Mérida originalmente se llamaba el "Plan México", pero la comparación directa con el Plan Colombia se consideró como una desventaja debido al rechazo a la posible presencia del personal de seguridad civil y militar estadounidense en el territorio mexicano (Cuestas Zamora, Marínez Caicedo, Molina Vanegas 2012: 289). Teniendo esto en cuenta, Iniciativa Mérida fue presentada al público como un reconocimiento de la co-responsabilidad de EE.UU. y un pedido de mayor cooperación, iniciado por México, en un asunto preocupante para ambos países (Haugaard, Isacson, Johnson 2001: 3). En contraste con el Plan Colombia, la Iniciativa Mérida no incluye una presencia militar activa de EE.UU. en México, en gran parte debido a las preocupaciones mexicanas sobre la soberanía nacional derivada de conflictos pasados con el vecino del norte.

La Iniciativa Mérida fue destinada principalmente a combatir el tráfico de drogas, la delincuencia transnacional y el terrorismo en México y algunos países de América Central y el Caribe. Durante el primer año de vigencia, la Iniciativa Mérida proporcionó a México US \$ 400 millones en equipo y entrenamiento. La Iniciativa Mérida incluía un monto adicional de US \$ 65 millones 
para los países centroamericanos, Haití y la República Dominicana (Cadena Montenegro 2010: 55). El paquete final de financiamiento de 2008 requería que el Departamento de Estado informara al Congreso de EE.UU. sobre las medidas específicas que México tomaría para abordar las preocupaciones de los derechos humanos. Las áreas a ser reportadas incluyen esfuerzos para mejorar la transparencia y rendición de cuentas de la policía local, regional y nacional; consultas con organizaciones mexicanas de los derechos humanos y la sociedad civil; el trabajo para asegurar investigaciones dirigidas por civiles sobre presuntas violaciones de los derechos humanos; y la prohibición del uso de testimonios obtenidos mediante tortura (Olson 2017).

La Iniciativa Mérida, como el Plan Colombia, significa de hecho la militarización de la lucha antidrogas, pero al mismo tiempo no proporciona fondos para los temas como el desarrollo, la reducción del consumo y la demanda de narcóticos, así como otros problemas socioeconómicos que enfrenta México (Bailey 2011). La administración del presidente Barack Obama ligeramente modificó la Iniciativa Mérida lanzada por Bush y estableció los cuatro pilares: afectar la capacidad operativa del crimen organizado; institucionalizar la capacidad para mantener el Estado de Derecho; crear la estructura fronteriza del siglo XXI; construir comunidades fuertes y resilientes (Embajada 2017). La Iniciativa Mérida se concentró en el apoyo de EE.UU. y también de Colombia a México, principalmente dirigido al entrenamiento de los cuerpos policiacos, mejoramiento de la infraestructura de las instituciones de seguridad para combatir el tráfico de drogas, así como la renovación del sistema de justicia en México (Rosen, Zepeda Martínez 2014: 189). Entre las instituciones norteamericanas involucradas se encuentran el Departamento de Estado y el Departamento de Justicia, el Consejo Nacional de Seguridad (NSC - National Security Council), el Pentágono, la Agencia Central de Inteligencia (CIA - Central Intelligence Agency), el Buró Federal de Investigaciones (FBI - Federal Bureau of Investigation), la Administración de Cumplimiento de Leyes sobre las Drogas (DEA - Drug Enforcement Administration) y, por parte de México, el Congreso de la Unión, la Secretaría de la Defensa Nacional (SEDENA), la Secretaría de Marina (SEMAR), la Secretaría de Gobernación (SEGOB) a través de la Comisión Nacional de Seguridad (CNS), la Procuraduría General de la República (PGR) y el Centro de Investigación y Seguridad Nacional (CISEN) (Cadena Montenegro 2010: 54).

Después de asumir el cargo de presidente de México, Felipe Calderón Hinojosa, su declaración de guerra antinarco y el lanzamiento de la Iniciativa Mérida, floreció la cooperación en seguridad entre México y Colombia. En el 2007 se realizaron cuatro reuniones en materia de seguridad México-Colombia, y en el 2008 se realizó la III Reunión del GANSJ. El resultado final del trabajo del GANSJ fueron los acuerdos binacionales firmados el 1 de agosto de 2011: el "Tratado de extradición” y el "Tratado sobre traslado de personas condenadas para la ejecución de sentencias penales”.

El compromiso de los colombianos en México aumentó aún más después de las elecciones presidenciales de 2010 ganadas por Juan Manuel Santos
La cooperación de Colombia y México en la lucha contra el narcotráfico: Esperanzas y temores asociados con la implementación del modelo colombiano de la seguridad pública en México

Paweł Trefler Raúl Ruiz Canizales Benjamín Ortega Guerra 
Calderón. Con el apoyo de EE.UU., Santos anunció en el 2012 la iniciativa "Diplomacia para la Seguridad" que iba a servir para transferir a otros países la experiencia colombiana en la lucha contra la delincuencia transnacional y el terrorismo. En este caso, el presidente de EE.UU. Barack Obama dijo lo siguiente: "Primeramente, es importante reconocer que Colombia ha logrado inmensos avances en seguridad (...) El éxito también está teniendo un impacto que va más allá de sus fronteras, pues Colombia comparte su pericia en seguridad con aliados en la región y en otras partes." (Gómez 2012). Por su parte, el ex asistente del Secretario Adjunto de la Oficina Internacional de Narcóticos y Aplicación de la Ley (INL - Bureau of International Narcotics and Law Enforcement Affairs) añadió: "Es un dividendo que obtenemos por haber invertido más de US\$9.000 millones en apoyo al Plan Colombia” (Arratia Sandoval 2015: 10).

EE.UU. quiere que los colombianos entrenen a los funcionarios de las fuerzas de seguridad y del poder judicial de México y otros países de América Latina y el Caribe, e incluso Afganistán. Según la Oficina de Asuntos Internacionales de la Policía Nacional de Colombia, entre 2009 y 2013 se proporcionó entrenamiento policial y militar a 21.949 personas de 47 países en habilidades tales como la interdicción terrestre, aérea, marítima, y en ríos, testimonio policial, explosivos, operaciones de inteligencia, operaciones psicológicas, entre otros (Tickner, Morales 2015: 193).

La participación de los colombianos en el entrenamiento de las fuerzas de seguridad latinoamericanas y de otras partes del mundo cuesta mucho menos a los contribuyentes estadounidenses en comparación con la participación directa de las fuerzas americanas, y en segundo lugar, que es muy importante, le permite a EE.UU. dejar una "huella menos perceptible" en varios países sin la impresión negativa de una gran presencia militar (Kinosian, Lindsay-Poland, Haugaard 2015). Según Arlene B. Tickner y Mateo Morales (2015: 196), se puede notar que: "En la era pos-Iraq, pos-Afganistán y poscrisis financiera, la importancia de los enfoques de 'huella ligera' ha crecido a la par con la adversidad de la opinión pública estadounidense hacia la participación militar directa en contextos que no son percibidos como una amenaza inmediata a los intereses vitales de seguridad de ese país". Además, "el uso de terceros que actúan como proxy sirve para crear lo que se conoce como una 'negación plausible' -la negación del conocimiento o responsabilidad sobre actividades impopulares o ilegales." (Tickner, Morales 2015: 175) La alianza estratégica de Colombia y EE.UU. fue confirmada el 15 de abril 2012 durante una reunión de los presidentes Juan Manuel Santos y Barack Obama en el marco de la VI Cumbre de las Américas en Cartagena, Colombia. En este encuentro Colombia y EE.UU. acordaron profundizar y formalizar la coordinación de actividades de cooperación en seguridad en el hemisferio y en África Occidental mediante un Plan de Acción de Cooperación en Seguridad Regional (USCAP - U.S.-Colombia Action Plan on Regional Security Cooperation). Este Plan es una parte integral del Diálogo de Alto Nivel de Seguridad Estra- 
tégica (HLSSD - U.S.-Colombia High-Level Strategic Security Dialogue) y las reuniones de los expertos técnicos y funcionarios políticos que se centran en 4 áreas clave para ampliar la cooperación y alinearla con los objetivos y prioridades hemisféricas de seguridad ciudadana: narcotráfico, lucha contra el crimen, fortalecimiento institucional y el fomento de comunidades más seguras (USCAP 2012). El USCAP pone en marcha el Grupo de Coordinación para la Cooperación de Seguridad (SCCG - U.S.-Colombia Security Cooperation Coordinating Group) compuesto por funcionarios colombianos y estadounidenses de diversas agencias gubernamentales.

En este lugar vale la pena citar otra declaración de Obama de la VI Cumbre de las Américas en Cartagena: "Hemos seguido invirtiendo en programas como el Plan Colombia, pero ahora estamos trabajando con Colombia, considerando sus mejores prácticas alrededor de cuestiones como la seguridad de sus ciudadanos, para que no sólo EE.UU. sino también Colombia proporcionen asistencia y capacitación técnica a países de Centroamérica y el Caribe para encontrar maneras en que puedan duplicar parte del éxito que hemos visto en Colombia." (The White House 2015)

Para Colombia la iniciativa "Diplomacia para la Seguridad" es una muy buena herramienta de la política exterior por varias razones. La exportación de experiencias y desarrollos tecnológicos alcanzados en el campo militar durante décadas de conflicto armado interno abre nuevas vías de negocio para las empresas del sector de defensa de Colombia, por ejemplo la Industria Militar Colombiana (Indumil), la Corporación de Ciencia y Tecnología para el Desarrollo de la Industria Naval Marítima y Fluvial (Cotecmar) y la Corporación de la Industria Aeronáutica Colombiana (Ciac). En la realización de la "Diplomacia para la Seguridad” está implicado el Grupo Social y Empresarial de la Defensa (GSED), una organización que hace parte del Ministerio de Defensa Nacional de Colombia, la cual agrupa 18 entidades que apoyan la misión de las Fuerzas Militares y la Policía Nacional en Colombia. Dichas entidades cuentan con una amplia oferta de servicios de educación, transporte, recreación, vivienda y producción de equipos y elementos de uso militar y civil (Indumil 2017). Colombia recaba los argumentos para convertirse a un Estado asociado de la Organización del Tratado del Atlántico Norte (OTAN) (Sol Gastaldi 2014; Mora Witt 2017). A esto se suma la oportunidad de encontrar entre los países latinoamericanos un apoyo en la disputa marítima con Nicaragua, donde un fallo del Tribunal Internacional de La Haya favoreció los argumentos de Managua (Mercado 2013).

En cuanto a la dimensión práctica de la cooperación de Colombia con los países de Centroamérica y el Caribe, consiste principalmente en la asesoría en la implementación de los modelos colombianos de la policía (el sistema de mando único) y de las Fuerzas Militares. De acuerdo con USCAP, EE.UU. facilita el despliegue de instructores colombianos hacia los países participantes (Costa Rica, República Dominicana, El Salvador, Guatemala, Honduras y Panamá), así como el transporte de estudiantes de los mismos países para que concurran a escuelas militares y academias de policía en Colombia, mientras
La cooperación de Colombia y México en la lucha contra el narcotráfico: Esperanzas y temores asociados con la implementación del modelo colombiano de la seguridad pública en México

Paweł Trefler

Raúl Ruiz Canizales

Benjamín Ortega Guerra 
que Colombia financia los salarios y beneficios de sus capacitadores. Además, USCAP (no incluye México) cubre el costo de la capacitación militar de los estudiantes centroamericanos y caribeños dirigida por los colombianos en sus escuelas militares y policiales (Mercado 2013). En el 2012, la Comisión de Apropiaciones de la Cámara de Representantes de EE.UU. aprobó una partida de US\$18 millones para que Colombia entrenara a policías y militares de Centroamérica y el Caribe en la lucha contra el narcotráfico. Para entonces, el país había entrenado ya a unos 11.000 policías y militares de la región, particularmente de México, Honduras y Guatemala (El Tiempo 2012).

La cooperación de Colombia con México en la formación de los policías y militares mexicanos se empezó a intensificar y ampliar en el 2009 y se basa actualmente en el "Memorándum de entendimiento sobre cooperación mutua en materias de seguridad y defensa entre la Secretaría de Defensa Nacional de México, la Secretaría de Marina de México y el Ministerio de la Defensa Nacional de Colombia”, firmado el 8 de mayo de 2015 (Montes Acosta 2015). El Departamento de Defensa respalda intensamente los programas de entrenamiento en seguridad ofrecidos por Colombia, que consiste en que este país brinde los entrenadores los insumos técnicos y equipos, paga los salarios de los instructores. EE.UU. costea los viajes, alojamiento y alimentación de profesores y alumnos (Arratia Sandoval 2015: 21). Muchos de estos cursos se imparten en Colombia, por ejemplo en la Escuela Internacional del Uso de la Fuerza Policial para la Paz "CENOP” en la finca Los Pijaos, cuya fundación en 2008 fue financiada en parte con dinero de EE.UU. En Los Pijaos estaciona el famoso y prestigioso Comando Jungla, que es el grupo especial de la Policía Antinarcóticos de Colombia que inició en el año de 1989 con la colaboración del Servicio Aéreo Especial (SAS - Special Air Service) de Gran Bretaña y ahora tiene la reputación de ser la fuerza policial más eficiente y violenta del planeta. Otros importantes centros de adiestramiento son: la Base Militar de Tolemaida-Melgar con el Centro Nacional de Entrenamiento del Ejército Nacional de Colombia - CENAE, la Escuela de Lanceros y la Escuela de Helicópteros para las Fuerzas Armadas; la Base Militar de Fusagasuga (el Batallón de Infantería no. 39 Sumapaz); el Fuerte Militar Larandia (la Brigada de Fuerzas Especiales Contra el Narcotráfico). Sin embargo, cabe señalar que los instructores en la mayoría de los casos viajan a los países receptores, bien sea para entrenamientos cortos o por períodos prolongados para enseñar en escuelas de guerra o en academias de policía (Arratia Sandoval 2015: 21) y además los funcionarios mexicanos son directamente entrenados por los estadounidenses en México y EE.UU. De hecho, en el período 2013-2015 casi 6.000 militares y policías mexicanos fueron entrenados (Lindsay-Poland 2015).

Hay 7 áreas temáticas principales del entrenamiento ofrecido por los colombianos a los militares, policías federales y estatales, así como para los fiscales y jueces mexicanos: desarrollo organizacional, lucha contra el narcotráfico, combate al crimen organizado transnacional, seguridad ciudadana, lucha contra la corrupción, derechos humanos y derecho internacional humanita- 
rio, fortalecimiento de capacidades operativas (Arratia Sandoval 2015: 14). Los cursos se versan sobre modelo de cultura institucional de fuerzas y cuerpos de seguridad de Estado, interdicción terrestre, marítima y aérea, prevención de consumo de drogas, investigación criminal, inteligencia y contrainteligencia policial y militar, antisecuestro, antiextorsión, entrenamiento canino militar, testimonio policial, derechos humanos, sistema penal acusatorio, lucha contra el lavado de activos, extinción de dominio, operaciones psicológicas, comando jungla y telemática, entrenamiento de aviación entre otros. Según el gobierno colombiano, la Policía Nacional de Colombia capacitó a 10.310 policías mexicanos entre 2009 y 2013 (Lindsay-Poland 2015). ${ }^{30}$ Las autoridades federales y estatales también disfrutan directamente de la experiencia de los colombianos mediante el empleo de los asesores en materia de seguridad provenientes de este país. En 2012 se hizo eco el caso del general Óscar Naranjo, exdirector de la Policía Nacional de Colombia (2007-2012), empleado por el presidente de México Enrique Peña Nieto.

\section{Esperanzas y temores asociados con la implementación del modelo colombiano de la seguridad pública en México}

México y Colombia son dos países latinoamericanos que se han caracterizado por presentar fenómenos sociales similares, pero al mismo tiempo también presentan sus respectivas particularidades, tales como el narcotráfico, la corrupción, la violencia, crímenes de Estado y la violación de los derechos humanos. Tales fenómenos se presentaron, primero, en Colombia, país que optó por generar el Plan Colombia y, posteriormente, en México, quien se basó en el primero para el diseño de la Iniciativa Mérida.

Con el objetivo de conocer la experiencia y opinión de expertos en la cooperación entre México y Colombia en materia de seguridad pública contra el narcotráfico, se llevó a cabo la aplicación de una encuesta, la cual contó con 8 preguntas mixtas realizadas a 10 académicos ( 2 mujeres y 8 hombres).

Una vez finalizada la aplicación de encuestas se llevó a cabo el vaciado de información; así como, la elaboración de gráficas representando los resultados obtenidos.
La cooperación de Colombia y México en la lucha contra el narcotráfico: Esperanzas y temores asociados con la implementación del modelo colombiano de la seguridad pública en México

Paweł Trefler

Raúl Ruiz Canizales

Benjamín Ortega Guerra

30 Entre 2010 y 2014 la Fuerza Pública de Colombia participó en el entrenamiento de unos 20.000 efectivos militares y policiales de 63 países, entre ellos El Salvador, Guatemala, Honduras, México, España, Italia y Afganistán, mediante convenios de cooperación entre los países (Marino García 2015). 


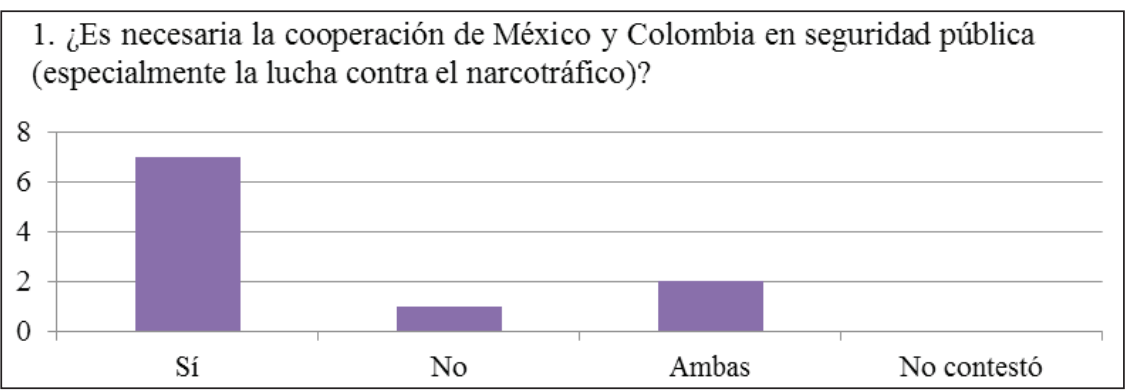

Fuente: elaboración propia.

Entre las principales razones por las cuales se considera necesaria la cooperación México-Colombia es:

- Aprender de la experiencia de ambos países los cuales se encuentran relacionados por la red del narcotráfico, y sus problemáticas.

- Rescatar lo valioso y los errores en el diseño e implementación de políticas públicas en seguridad.

- Enfrentar al crimen organizado y el narcotráfico a través del intercambio de información de inteligencia.

Se considera que no es necesaria ni recomendable la cooperación ya que los convenios están lejos de buscar seguridad pública; más bien ha militarizado y paramilitarizado la seguridad pública, violación de los derechos humanos, crímenes de Estado y de lesa humanidad.

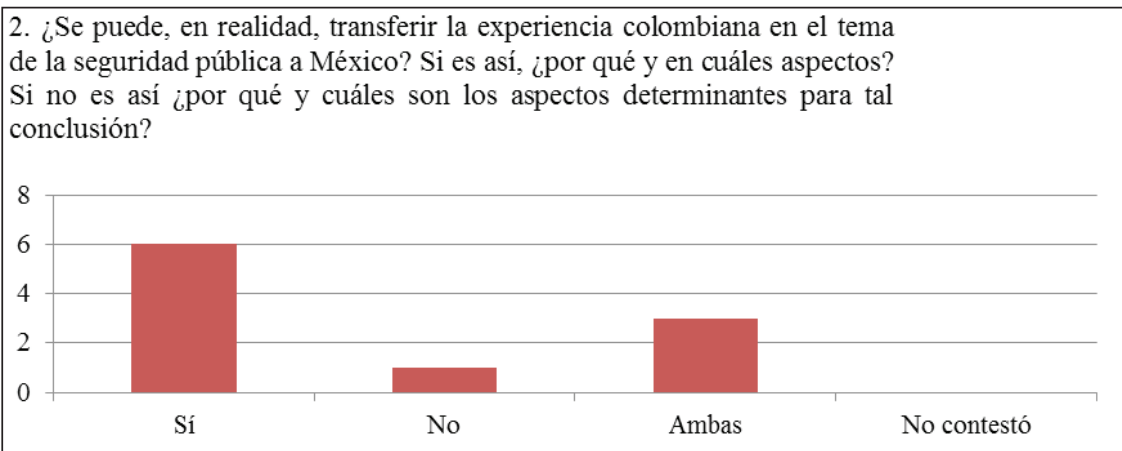

Fuente: elaboración propia.

Respecto a las personas que opinan que sí es transferible la experiencia, mencionan que se deben tomar en cuenta algunos aspectos tales como:

- La formación y profesionalización de las policías en sus distintos niveles y tipos de responsabilidad.

- La experiencia con el narcotráfico, el paramilitarismo y las guerrillas. 
- Aspectos organizacionales, directivos, de coordinación y operación dirigidos a la centralización de las policías a través de capacitación y entrenamiento de las policías de México.

- Intercambio de información de inteligencia.

- Tomar en cuenta las Buenas Prácticas y políticas criminales de Colombia que le permitieron reducir la violencia criminal.

En cuanto a los expertos que consideran que no es posible, mencionan que:

- Ninguna experiencia es transferible a otra.

- La seguridad pública funcional está en manos de las comunidades indígenas.

- El concepto transferible es mal utilizado ya que no se puede copiar tal cual un modelo, sino que se debe ajustar al contexto mexicano.

- Antes del combate de las drogas, México se debe enfocar en reducir los niveles de corrupción, debilidad institucional e impunidad.

- No se han tomado en cuenta los errores de Colombia y EE.UU.

3. ¿Cuáles son las ventajas y desventajas reales de esta cooperación?

$$
\text { घentajas } \square \text { Desventajas } \square \text { Ambas } \square \text { No contestó }
$$

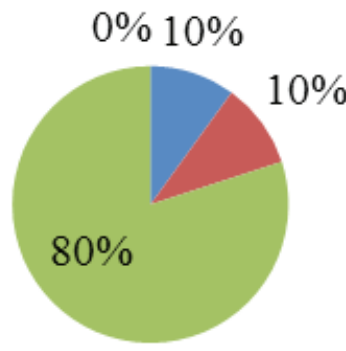

Fuente: elaboración propia.

Todos los encuestados contestaron a la pregunta respecto a las ventajas y desventajas reales de la cooperación. La mayoría (80\%) contestó que la cooperación trae consigo tanto ventajas como desventajas. Una persona (10\%) considera que la cooperación genera sólo ventajas y una (10\%) que genera exclusivamente desventajas.
La cooperación de Colombia y México en la lucha contra el narcotráfico: Esperanzas y temores asociados con la implementación del modelo colombiano de la seguridad pública en México

Paweł Trefler

Raúl Ruiz Canizales

Benjamín Ortega Guerra 


\begin{tabular}{ll}
\hline Ventajas & Desventajas \\
\hline $\begin{array}{l}\text { Aprender de la experiencia del otro } \\
\text { y mejorar. }\end{array}$ & Copiar sin ajustar al contexto. \\
\hline Cooperar contra grupos transnacionales. & Violación de DD.HH. \\
\hline Generación de agenda de inteligencia. & Paramilitarismo. \\
\hline Conocimiento de qué funciona y qué no. & No existencia de acuerdos de paz. \\
\hline $\begin{array}{l}\text { Aprendizaje de la negociación más allá de } \\
\text { políticas de guerra. }\end{array}$ & $\begin{array}{l}\text { Ejecuciones extrajudiciales } \\
\text { y desapariciones forzadas. }\end{array}$ \\
\hline Reducción de la violencia. & Crímenes de Estado y de lesa humanidad. \\
\hline & $\begin{array}{l}\text { Narco cultura como base social del } \\
\text { crimen organizado. }\end{array}$ \\
\cline { 2 - 2 } & \begin{tabular}{l} 
Falta de confianza y seguridad. \\
\cline { 2 - 2 }
\end{tabular} \\
$\begin{array}{l}\text { No se hace uso del diálogo ni de la } \\
\text { participación de la sociedad civil. }\end{array}$ & $\begin{array}{l}\text { Desconocimiento del programa por parte } \\
\text { de los operadores. }\end{array}$ \\
\hline
\end{tabular}

4. ¿Usted considera que durante los últimos 15 años esta cooperación ha ido por buen camino?

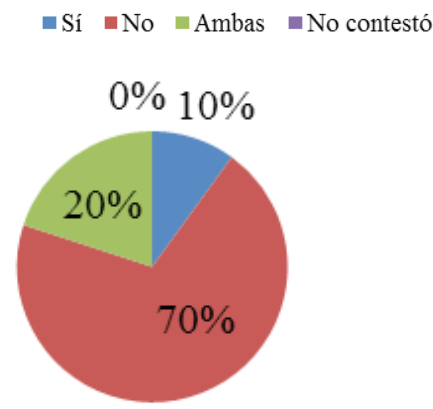

Fuente: elaboración propia.

El 100\% de los expertos encuestados contestaron a la pregunta realizada de los cuales el 70\% opina que la cooperación no ha ido por un buen camino, principalmente por lo siguiente:

- La existencia de violaciones de los derechos humanos por parte del Estado mexicano.

- La relación no es directa sino intermediada por EE.UU. y sus intereses.

- El arresto de grandes capos no ha afectado las organizaciones de narcotráfico sino que ha aumentado la variedad de los productos. 
- Continuidad de los altos índices de inseguridad.

- Inexistencia de la cooperación.

Las razones por las cuales se considera que sí ha ido por buen camino es porque la cooperación internacional puede ayudar a combatir las redes internacionales de narcotráfico y debido a que no hay datos de su mal funcionamiento.

5. A partir de su experiencia en el tema, ¿quién ha obtenido los mayores beneficios de esta cooperación, Colombia o México?¿Por qué?

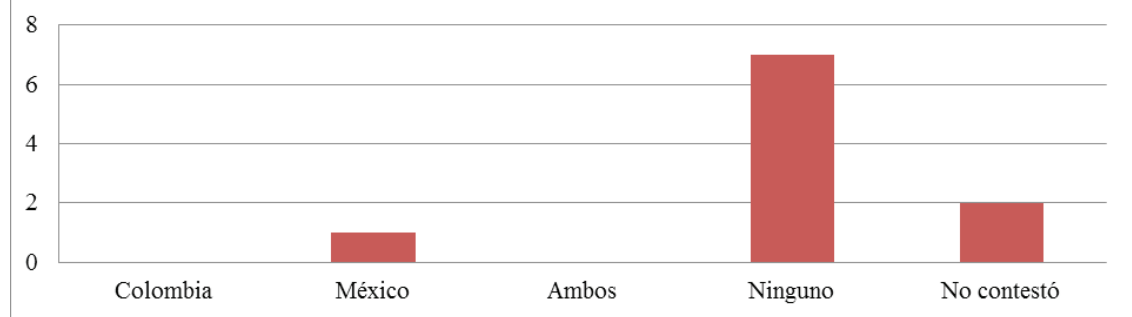

Del 100\% de los encuestados, únicamente el $80 \%$ respondió a la pregunta ¿quién ha obtenido los mayores beneficios de la cooperación? De los cuales el 70\% menciona que ninguno ha sido beneficiado y solo el 10\% considera que México. El por qué ninguno ha sido beneficiado se refiere principalmente a que los beneficiados son las organizaciones del narcotráfico y el beneficio ha sido exclusivamente económico. El 10\% que menciona que el beneficiado ha sido México se refiere a que tiene ventaja por tener como referente a Colombia, país que sufrió primero la problemática.

6. ¿Qué papel y qué beneficios tiene EE.UU. en esta cooperación?

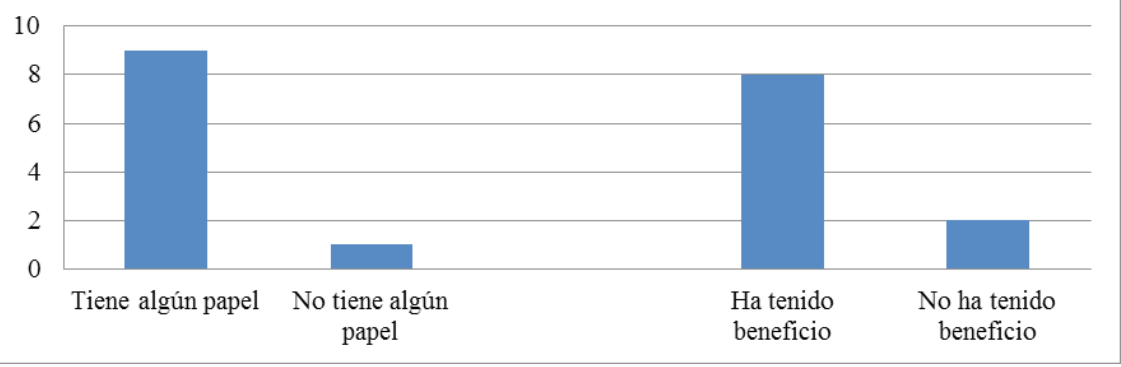

Del 100\% de los encuestados, el 90\% considera que EE.UU. juega algún papel en la cooperación entre México y Colombia, mientras el 10\% menciona que no juega papel alguno. Así mismo, el $80 \%$ opina que ha habido algún tipo de beneficio a partir de ésta. Entre los que respondieron que EE.UU.
La cooperación de Colombia y México en la lucha contra el narcotráfico: Esperanzas y temores asociados con la implementación del modelo colombiano de la seguridad pública en México

Paweł Trefler

Raúl Ruiz Canizales

Benjamín Ortega Guerra 
tiene algún papel en la colaboración se destaca que ha sido de las siguientes formas:

Propuesta de inicio de la colaboración.

- Financiado y capacitación de las fuerzas colombianas quienes posteriormente capacitan a las mexicanas (derechos humanos, seguridad humana y evaluación rigurosa).

- Establecido el terrorismo de Estado como política de seguridad pública.

- Papel central en la introducción de droga.

- Director y coordinador de los esfuerzos en seguridad e inteligencia.

- Introducción de políticas que corresponden a su agenda de seguridad nacional e imposición de su visión respecto a ésta.

En cuanto a los beneficios obtenidos se considera que ha sido:

- Para las fuerzas policiales de Colombia y México.

- Únicamente para EE.UU. en la obtención de información sensible respecto a los grupos armados de Colombia y México.

- Reducción del tráfico de drogas y de la inmigración.

- Control del tráfico de drogas.

7. ¿Cuál es el impacto de esta cooperación (México-Colombia) en el entorno internacional?

"Hay impacto $\quad$ No hay impacto $\quad$ No contestó $\quad$ No sabe

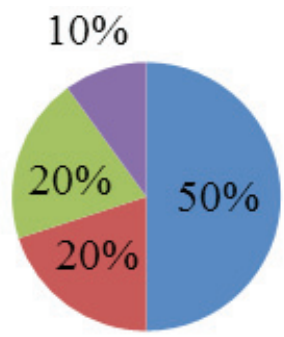

Fuente: elaboración propia.

Del 100\% de encuestados únicamente respondió el 80\%; de los cuales el $50 \%$ considera que la cooperación sí ha generado impacto; el $20 \%$ opina que no ha habido impacto y el $10 \%$ no sabe. Del $50 \%$ que opina que sí hay impacto, menciona que es en cuestión de:

- Militarización de las calles.

- Abusos, violación de los derechos humanos, violencia y crímenes.

- Estabilización de Centro América.

- Mejora en las condiciones para la inversión productiva.

- Reducción de la migración hacia EE.UU.

- Vigencia del modelo penal y médico de prohibición. 
Del 20\% que considera que no hay impacto alguno, refiere que no existe cooperación y que para su existencia Colombia debe lograr primero la paz.

8. ¿Qué factores considera usted prioritarios para la evaluación del futuro de esta cooperación entre México y Colombia en el tema específico de la lucha contra el narcotráfico?

A continuación se enlistan los factores prioritarios:

1. Método y la capacidad del Estado en ofrecer alternativas.

2. Cooperación más allá de la seguridad.

3. Aplicación de un programa articulado en torno a las expectativas y potencialidades de cada nación.

4. Intercambio de personal táctico.

5. Cantidad de individuos entrenados.

6. Tipo de cooperación y efectividad de ésta.

7. Incremento o disminución de la violencia.

8. Acuerdos concretos de cooperación.

9. Intercambio de información policial y de seguridad.

10. Captura de criminales mediante operativos.

11. Reducción de la militarización.

12. Niveles de violencia.

13. Violaciones de los derechos humanos.

14. Corrupción.

15. Niveles de consumo doméstico de drogas.

16. Pobreza y otros factores económicos.

17. Intercambio de experiencias preventivas no penales.

18. Que Colombia controle a las FARC.

A partir del análisis de los resultados obtenidos se concluye que:

La cooperación entre Colombia y México para la seguridad ciudadana es necesaria para aprender de las experiencias de ambos respecto de las problemáticas que presentan y al diseño e implementación de políticas públicas.

- No obstante, sólo es posible si, al tomar las experiencias del otro país, esto se realiza tomando en cuenta el contexto del país receptor y se ajustan los modelos a sus características propias.

- La experiencia de Colombia no puede ser transferida pero sí aprendida por México en cuanto a formación y profesionalización de las policías; organización, dirección, coordinación y operación de las policías dirigidas a su centralización; y Buenas Prácticas y políticas criminales. Sin embargo, para ello México se debe enfocar en reducir los niveles de corrupción, debilidad institucional e impunidad.
La cooperación de Colombia y México en la lucha contra el narcotráfico: Esperanzas y temores asociados con la implementación del modelo colombiano de la seguridad pública en México

Paweł Trefler

Raúl Ruiz Canizales

Benjamín Ortega Guerra 
- A pesar de que los expertos mencionaron en un mismo porcentaje la existencia de ventajas y desventajas; es posible detectar que se enumeran mayores desventajas que ventajas respecto a la cooperación. Asimismo, se considera que la cooperación no ha ido por buen camino, esto principalmente por las violaciones de los derechos humanos, militarización, crímenes de Estado y olas de violencia, las cuales -en lugar de disminuir- han aumentado.

- EE.UU. ha sido el país protagonista en la cooperación, ya sea como intermediario, proveedor de recursos y conocimiento o de imponer su agenda de seguridad nacional e ideologías.

\section{Conclusiones}

El impacto de la industria de las drogas, en la cual están involucradas las grandes organizaciones criminales de Colombia, México y EE.UU., es muy fuerte y amplio: cubre principalmente la Región Andina, América Central, el Caribe, EE.UU. y Canadá, y en una escala más amplia el resto del mundo. El narcotráfico es una gran fuente de ingresos para los criminales, políticos, empresarios, financieros, y el combate a este problema sigue siendo causa de las graves violaciones de seguridad pública (OAS 2013). Por lo tanto, en la lucha contra este fenómeno están involucradas enormes fuerzas y recursos financieros. El efecto secundario de las acciones dirigidas a la destrucción de la narcoindustria, que implican principalmente la reducción de la oferta de drogas en su lugar de producción, eliminación de los capos, cárteles y rutas de envío de los narcóticos, es la violencia omnipresente, la corrupción, la impunidad y la debilidad institucional de muchos países latinoamericanos y caribeños.

Si bien es cierto que México y Colombia comparten ciertos patrones culturales, también lo es que cada una de estas naciones cuenta con pautas que podrían considerarse disímbolas. Un ejemplo de ello es que en la lucha contra con los cárteles de las drogas, mientas Colombia parecía implementar una estrategia de enfrentamiento de manera proporcional, México, por su parte, durante el sexenio del expresidente Felipe Calderón, comenzó a desplegar una estrategia de combate que generó un "sospechosismo" fundado en la percepción de que uno de los cárteles -el de Sinaloa- gozaba de protección.

Durante el gobierno de Calderón el Cartel de Sinaloa, liderado por el Chapo Guzmán, fue la organización criminal con menos detenidos y encarcelados o abatidos. El craso problema de corrupción que ha permeado en casi todas las instituciones de México ha sido un factor determinante en la generación de expectativas poco favorables para la Iniciativa Mérida (y otros de la misma naturaleza). De hecho, de los US\$2.624 millones que el gobierno de los EE.UU. ha transferido en los últimos 10 años, en el gobierno de Donald Trump se tiene previsto una asignación de tan sólo US\$129 millones. No sólo eso, sino que en la cadena de amagos que el presidente Trump ha depositado sobre México, 
aquel anunció en el mes de enero del presente año que se revisarán todos los fondos aportados a México en los últimos 5 años.

No hay que olvidar que en la experiencia mexicana la Iniciativa Mérida ponía en juego un cambio de inercias tanto en lo institucional como en los sujetos involucrados, pero a partir de los sucesos de los 43 desaparecidos de Ayotzinapa así como otras circunstancias del mismo calado y del mismo impacto (violaciones de los derechos humanos, desapariciones forzadas, secuestro de migrantes, etc.), el gobierno de Barack Obama decidió congelar US\$5 millones, mismo que fueron liberados en octubre del año pasado. En lo que va del gobierno de Enrique Peña Nieto, México ha recibido tan solo US\$ 672 millones para la Iniciativa Mérida. Muy poco frente a los casi US\$ 2.000 millones que se recibieron en el sexenio pasado (Urrutia 2017). La cifra que ya no se destinará en el 2018 para diplomacia norteamericana ni para apoyo foráneo asciende a US\$ 10.900 millones de dólares, lo que equivale a un 29\% respecto de este año. En el fondo de toda esta cascada de recortes anunciados por el presidente Trump se encuentra el factor 'sospechosismo', fundado a su vez en una percepción de corrupción que el presidente de EE.UU. tiene sobre México. Ese dinero (US\$ 10.900 millones) estará destinado ahora -advirtió Trump - a la construcción del muro.

Como vemos, las expectativas de continuidad de la Iniciativa Mérida y del Plan Paz Colombia no son nada alentadoras para los próximos años. Mientras el problema de la corrupción siga acechando a las instituciones en México, difícilmente podríamos incidir en la perspectiva del actual presidente de los EE. UU. De hecho, los últimos acontecimientos (fuga del Chapo Guzmán, las constantes violaciones de los derechos humanos, los feminicidios, los casos de los exgobernadores procesados por desvío de recursos y enriquecimiento ilícito, etc.) han abonado en la mente del presidente de nuestro país vecino del norte para arremeter una y otra vez contra la clase política mexicana.

Ante el escenario descrito en los párrafos anteriores, los gobiernos de Colombia y México tienen la urgente necesidad de redefinir las estrategias de colaboración para el combate al crimen organizado. Pero en el caso de México, primero debe garantizar la implementación de verdaderos mecanismos de combate a la corrupción, ya que, como vimos, el problema no es menor, es el factor que ha obstaculizado constantemente las posibilidades de que los objetivos de la Iniciativa Mérida se hayan logrado de manera mucho más exitosa, y no sólo mediáticamente.
La cooperación de Colombia y México en la lucha contra el narcotráfico: Esperanzas y temores asociados con la implementación del modelo colombiano de la seguridad pública en México

Paweł Trefler

Raúl Ruiz Canizales

Benjamín Ortega Guerra 


\section{Bibliografía}

Acuerdo de cooperación en materia de lucha contra el tráfico ilícito de estupefacientes y sustancias psicotrópicas entre el gobierno de los Estados Unidos Mexicanos y el gobierno de la República de Colombia, Bogotá, 17 de enero de 1997.

Alianza del Pacífico (2017), ¿Qué es la Alianza?, disponible en: //alianzapacifico.net/que-esla-alianza/, fecha de consulta: 02.05.2017.

AMECID (2016), Proyecto de Integración y Desarrollo de Mesoamérica, Agencia Mexicana de Cooperación Internacional para el Desarrollo, disponible en: http://www.gob.mx/amexcid/ acciones-y-programas/proyecto-de-integracion-y-desarrollo-de-mesoamerica-29336, fecha de consulta: 02.05.2017.

Ardila M., Tickner A., Cardona D. (eds.) (2002), Prioridades y desafíos de la política exterior colombiana, FESCOL, Bogotá.

Arratia Sandoval E. (2015), La vía colombiana: Las implicancias de la diplomacia para la seguridad en América Latina, "Cuadernos de Estudios Estratégicos", Cuaderno de Trabajo no. 14/2015, disponible en: http://www.asociacioncolegiosdefensaiberoamericanos.org/ acdibero/Publicaciones/Cuaderno+de+Trabajo+N\%C2\%BA14.pdf, fecha de consulta: 02.05.2017.

Astorga L. (2015), ¿Qué querían que hiciera? Inseguridad y delincuencia organizada en el gobierno de Felipe Calderón, Grijalbo, México.

Astorga L. (2015a), Drogas sin fronteras, Debolsillo, México.

Bagley B. M. (2001), Drug trafficking, political violence and U.S. policy in Colombia in the 1990s, disponible en: https://www.as.miami.edu/media/college-of-arts-and-sciences/ content-assets/international-studies/documents/publications/Bagley Drugs and violence final3.pdf, fecha de consulta: 02.05.2017.

Bagley B. M. (2011), Carteles de la droga: de Medellín a Sinaloa, razonpublica.com, 21 de febrero, disponible en: http://www.razonpublica.com/index.php/conflicto-drogas-ypaz-temas-30/1821-carteles-de-la-droga-de-medellin-a-sinaloa.html, fecha de consulta: 02.05.2017.

Bailey J. (2011), Plan Colombia and the Merida Initiative: Policy twins or distant cousins? en: Morales I. (ed.), National Solutions to Trans-border Problems?: The Governance of Security and Risk in a post-NAFTA North America, Ashgate Publishing, Surrey.

Benítez Manaut R. (2014), Mexico-Colombia: U.S. assistance and the fight against organized crime, en: Arnson C. J., Olson E. L., Zaino Ch. (2014), One Goal: Two Struggles: Confronting Crime and Violence in Mexico and Colombia, "Woodrow Wilson Center Reports on the Americas", no. 32, Washington D.C., disponible en: https://www.wilsoncenter.org/sites/ default/files/Colombia_Mexico_Final.pdf, fecha de consulta: 02.05.2017.

Benítez Manaut R., Rodríguez Luna Á. A. (2009), Iniciativa Mérida, seguridad nacional y soberanía, en: Velázquez Flores R., Prado Lallande J. P. (coord.), La Iniciativa Mérida: ¿Nuevo paradigma de cooperación entre México y Estados Unidos en seguridad? UNAM, UAP, SITESA, México.

Bowden M. (2010), Matar a Pablo Escobar, RBA Libros, Barcelona.

Buscaglia E. (2015), Lavado de dinero y corrupción política. El arte de la delincuencia organizada internacional, Debate, México. 
Cadena Montenegro J. L. (2010), Geopolítica del narcotráfico. México y Colombia: la equivocación en el empleo de las fuerzas militares, "Revista Mexicana de Ciencias Politícas y Sociales”, vol. LII, no. 210, septiembre-diciembre, disponible en: http://www.redalyc.org/ articulo.oa?id=42118500003, fecha de consluta: 02.05.2017.

Cámara de Senadores (2013), Dictamen por el que se ratifica el nombramiento que el ciudadano Presidente de la República hace en favor del ciudadano Arnulfo Valdivia Machuca, como Embajador Extraordinario y Plenipotenciario de México en la República de Colombia, Cámara de Senadores, LXII Legislatura, Comisiones Unidas de Relaciones Exteriores y de Relaciones Exteriores, América Latina y el Caribe, 25 de septiembre, disponible en: http:// sil.gobernacion.gob.mx/Archivos/Documentos/2013/12/asun_3050463_20131202_13859 98566.pdf, fecha de consulta: 02.05.2017.

Carlsen L. (2007) ¿Guerra contra el narcotráfico o la militarización de México? portal América Latina en Movimiento, 12 de julio, disponible en: http://www.alainet.org/es/ active/18580, fecha de consulta: 02.05.2017.

Carrión F., Dammert G. M. (comp.) (2009), Economía política de la seguridad ciudadana, Facultad Latinoamericana de Ciencias Sociales (FLACSO, sede Ecuador), Municipio del Distrito Metropolitano de Quito (MDMQ), Quito.

Carvajal L., Pardo R. (2002), Internacionalización del conflicto y procedimientos de paz, en: Ardila M., Tickner A., Cardona D. (eds.), Prioridades y desafíos de la política exterior colombiana, FESCOL, Bogotá.

CDHN (1998), Principios rectores de los desplazamientos internos, Comisión de Derechos Humanos de las Naciones Unidas, E/CN.4/1998/53/Add.2, 11 de febrero, disponible en: www.oas.org/.../principios_rectores_desplazamientos_internos.pdf, fecha de consulta 02.05.2017.

Croda R. (2015), La “mexicanización” de Colombia, "Proceso", 21 de febrero, disponible en: http://www.proceso.com.mx/396552/la-mexicanizacion-de-colombia, fecha de consulta: 02.05.2017.

Cruz Cruz M. (2009), Plan Colombia e Iniciativa Mérida: Piezas estratégicas de la hegemonía continental, en: Velázquez Flores R., Prado Llorente J. P. (coord.), La Iniciativa Mérida: ¿Nuevo paradigma de cooperación entre México y Estados Unidos en seguridad? UNAM, UAP, SITESA, México.

Cuestas Zamora E., Marínez Caicedo J., Molina Vanegas N. (2012) ¿El modelo antidrogas colombiano es exitoso y puede ser exportado y aplicado a Mexico? "Criterios", vol. 5, no. 2, julio-diciembre de 2012, disponible en: http://revistas.usb.edu.co/index.php/criterios/ article/viewFile/1978/1721, fecha de consulta: 02.05.2017.

DOS (2017), International Narcotics Control Strategy Report, U.S. Department of State, vol. I, Drug and Chemical Control, March 2017, disponible en: https://www.state.gov/ documents/organization/268025.pdf, fecha de consulta: 02.05.2017.

DOS (2017a), Central America Regional Security Initiative, U.S. Department of State, disponible en: https://www.state.gov/j/inl/rls/fs/2017/260869.htm, fecha de consulta: 02.05.2017.

DOS (2017b), Merida Initiative, U.S. Department of State, disponible en: https://www.state. gov/j/inl/merida/, fecha de consulta: 02.05.2017.

DOS (2017c), The Caribbean Basin Security Initiative, U.S. Department of State, disponible en: https://www.state.gov/p/wha/rt/cbsi/, fecha de consulta: 02.05.2017.
La cooperación de Colombia y México en la lucha contra el narcotráfico: Esperanzas y temores asociados con la implementación del modelo colombiano de la seguridad pública en México

Paweł Trefler Raúl Ruiz Canizales Benjamín Ortega Guerra 
DPA (2015), The Federal Drug Control Budget: New rhetoric, same failed drug war, Drug Policy Alliance, February 2015, disponible en: https://www.drugpolicy.org/sites/default/ files/DPA_Fact_sheet_Drug_War_Budget_Feb2015.pdf, fecha de consulta: 02.05.2017.

El Tiempo (2012), Con dinero de EE.UU., Colombia exportaría seguridad, "El Tiempo", 19 de mayo, disponible en: http://www.eltiempo.com/archivo/documento/MAM-5434522, fecha de consulta: 02.05.2017.

El Tiempo (2016), Las estrategias que marcaron el ocaso del grupo guerrillero, "El Tiempo", 26 de agosto, disponible en: http://www.eltiempo.com/politica/proceso-de-paz/plancolombia-y-plan-patriota-49654, fecha de consulta: 02.05.2017.

Embajada de Colombia en México (2017), Mecanismos bilaterales, disponible en: http:// mexico.embajada.gov.co/colombia/mecanismos_bilaterales, fecha de consulta: 02.05.2017.

Embajada y consulados de EE.UU. en México (2017), Iniciativa Mérida, disponible en: https://mx.usembassy.gov/es/nuestra-relacion/temas-bilaterales/iniciativa-merida/, fecha de consulta: 02.05.2017.

GAO (2016), Firearms trafficking, U.S. Government Accountability Office, Report to Congressional Requesters, January, disponible en: http://www.gao.gov/assets/680/674570. pdf, fecha de consulta: 02.05.2017.

Gómez Maseri S. (2012), 'Colombia muestra que el éxito es posible’: Barack Obama, entrevista con el Presidente Barack Obama, "El Tiempo", 13 de abril, disponible en: http:// www.eltiempo.com/Multimedia/especiales/cumbre-de-americas-2012/ARTICULOWEB-NOTA_INTERIOR_MULTIMEDIA-11557121.html, fecha de consulta: 02.05.2017.

Gómez Maseri S. (2017), Asocian aumento de consumo de cocaína en Estados Unidos con Colombia, "El Tiempo", 18 de marzo, disponible en: http://www.eltiempo.com/mundo/ eeuu-y-canada/alerta-por-aumento-de-consumo-de-cocaina-en-estados-unidos-69142, fecha de consulta: 02.05.2017.

Grillo I. (2012), El Narco: En el corazón de la insurgencia criminal mexicana, Tendencias, México.

Haugaard L., Isacson A., Johnson J. (2011), Un relato aleccionador: Las lecciones del Plan Colombia para la política exterior estadounidense hacia México y otros países, LAWGEF-CIPWOLA, noviembre, disponible en: www.lawg.org/.../Mexico/lawgef\%20cautionary\%20 tale\%20sp\%20f.pdf, fecha de consulta: 02.05.2017.

Holguín Cuéllar M. Á. (2015), Memoria al Congreso 2014-2015, Ministerio de Relaciones Exteriores de la República de Colombia, Bogotá, disponible en: https://www.cancilleria. gov.co/sites/default/files/FOTOS2015/memorias_al_congreso_2014-2015.pdf, fecha de consulta: 02.05.2017.

HRW (2001), La 'Sexta División'. Relaciones militares-paramilitares y la política estadounidense en Colombia, Human Rights Watch, 4 de octubre, disponible en: https://www.hrw.org/ es/report/2001/10/04/la-sexta-division/relaciones-militares-paramilitares-y-la-politicaestadounidense, fecha de consulta: 02.05.2017.

Indumil (2017), ¿Qué es el Grupo Social y Empresarial de la Defensa?, 1 de marzo, disponible en: https://www.indumil.gov.co/noticia/comite-coordinador-del-gsed-se-reunira-para-estudiarproyectos-estrategicos-2017/, fecha de consulta: 02.05.2017.

Kinosian S., Lindsay-Poland J., Haugaard L. (2015), Estados Unidos no debería exportar el 'éxito' de la guerra de Colombia contra las drogas, InSightCrime, 10 de julio, disponible en: http://es.insightcrime.org/analisis/estados-unidos-no-deberia-exportar-exito-guerracolombia-contra-drogas, fecha de consulta: 02.05.2017. 
Lindsay-Poland J. (2015), The expanding geography of training Mexico's police and soldiers, American Friends Service Committee (AFSC), 29 de noviembre, disponible en: https:// www.afsc.org/story/expanding-geography-training-mexico $\%$ e $2 \% 80 \% 99$ s-police-andsoldiers, fecha de consulta: 02.05.2017.

Lustig R. (2010), Can Mexico and Afghanistan learn lessons from Colombia? BBC News, 7 de octubre, disponible en: http://www.bbc.co.uk/news/mobile/world-latin-america-11492357, fecha de consulta: 02.05.2017.

Mack J. (2001), Plan Colombia and the Andean Regional Initiative, testimony before the Subcommittee on the Western Hemisphere, Washington D.C. 28 de junio, disponible en: https://2001-2009.state.gov/p/inl/rls/rm/jun_aug/3847.htm, fecha de consulta: 02.05.2017.

Marino García C. F. (2015), Fuerzas Armadas colombianas entrenan a sus pares de todo el mundo,"Diálogo", 29 de enero, disponible en: https://dialogo-americas.com/es/articles/ fuerzas-armadas-colombianas-entrenan-sus-pares-de-todo-el-mundo, fecha de consulta: 02.05.2017.

Mercado J. G. (2013), Colombia exporta su modelo de seguridad, "El Tiempo", 7 de octubre, disponible en: http://www.eltiempo.com/archivo/documento/CMS-13105572, fecha de consulta: 02.05.2017.

Montes Acosta D. F. (2015), Presidentes de Colombia y México firman acuerdo para combatir a narcos, "El Tiempo", 8 de mayo, disponible en: http://www.eltiempo.com/archivo/ documento/CMS-15715816, fecha de consulta: 02.05.2017.

Mora Witt M. (2017), ¿La OTAN en América Latina?, "El Telégrafo", 7 de enero, disponible en: http://www.eltelegrafo.com.ec/noticias/columnistas/1/la-otan-en-america-latina, fecha de consulta: 02.05.2017.

Morales I. (ed.) (2011), National solutions to trans-border problems?: The governance of security and risk in a post-NAFTA North America, Ashgate Publishing, Surrey.

Nixon R. (1971), 203 - Special Message to the Congress on drug abuse prevention and control, 17 de junio, Washington D.C., disponible en: http://www.presidency.ucsb.edu/ ws/?pid=3048, fecha de consulta: 02.05.2017.

Norman J. (2016), No new US president will mess with Plan Colombia's 'success', "Colombia Reports", 25 de abril, disponible en: http://colombiareports.com/no-new-us-presidentwill-mess-plan-colombias-success/, fecha de consulta: 02.05.2017.

Noticias Terra (2017), México y Colombia fortalecerán vínculos estrategicos, "Noticias Terra", 7 de febrero, disponible en: https://noticias.terra.com.mx/mexico/mexico-y-colombiafortaleceran-vinculos-estrategicos, $412 \mathrm{f} 2677 \mathrm{~b} 7 \mathrm{ba} 1 \mathrm{ce} 9 \mathrm{a} 0836 \mathrm{e} 24 \mathrm{f} 9738 \mathrm{fbbyquty} 2 \mathrm{hv} \cdot \mathrm{html}$, fecha de consulta: 02.05.2017.

Notigape (2017), Definirán primera reunión del Comité Estratégico Colombo-Mexicano, 7 de febrero, disponible en: http://www.notigape.com/contenido/126287, fecha de consulta: 02.05.2017.

OAS (2013), The drug problem in the Americas, Organization of American States, disponible en: https://www.oas.org/documents/eng/press/introduction_and_analytical_report.pdf, fecha de consulta: 02.05.2017.

Olson E. L. (2017), The Mérida Initiative and shared responsibility in U.S.-Mexico security relations. How a longstanding initiative has shaped cross-border cooperation, "The Wilson Quarterly", Winter, disponible en: http://wilsonquarterly.com/quarterly/after-the-storm-
La cooperación de Colombia y México en la lucha contra el narcotráfico: Esperanzas y temores asociados con la implementación del modelo colombiano de la seguridad pública en México

Paweł Trefler Raúl Ruiz Canizales Benjamín Ortega Guerra 
in-u-s-mexico-relations/the-m-rida-initiative-and-shared-responsibility-in-u-s-mexicosecurity-relations/, fecha de consulta: 02.05.2017.

Pabón Ayala N., Ortega Gómez F. (2009), Seguridad ciudadana en Colombia y cooperación internacional, en: Carrión F., Dammert G. M. (comp.), Economía política de la seguridad ciudadana, Facultad Latinoamericana de Ciencias Sociales (FLACSO, sede Ecuador), Municipio del Distrito Metropolitano de Quito (MDMQ), Quito.

Pardo Veiras J. L. (2016), México cumple una década de duelo por el fracaso de la Guerra contra el Narco, "The New York Timies", 7 de septiembre, disponible en: https://www. nytimes.com/es/2016/09/07/mexico-cumple-una-decada-de-duelo-por-el-fracaso-de-laguerra-contra-el-narco/, fecha de consulta: 02.05.2017.

Presidencia de la República (2015), Elevan los Presidentes Enrique Peña Nieto y Juan Manuel Santos a nivel estratégico la relación entre México y Colombia, 7 de mayo, disponible en: https://www.gob.mx/presidencia/prensa/elevan-los-presidente-enrique-pena-nieto-yjuan-manuel-santos-a-nivel-estrategico-la-relacion-entre-mexico-y-colombia, fecha de consulta: 02.05.2017.

PSD (2003), Política de Defensa y Seguridad Democrática, Presidencia de la República, Ministerio de Defensa Nacional, República de Colombia, disponible en: http://www.oas. $\mathrm{org} / \mathrm{csh} / \mathrm{spanish} /$ documentos/colombia.pdf, fecha de consulta: 02.05.2017.

Ribando Seelke C., Finklea K. (2017), US.-Mexican security cooperation: The Mérida Initiative and beyond, Congressional Research Service Report prepared for Members and Commitees of Congress, 18 de enero, disponible en: https://fas.org/sgp/crs/row/R41349. pdf, fecha de consulta: 02.05.2017.

Rodríguez Beruff J., Cordero G. (2005), La tercera frontera: La guerra contra las drogas en el Caribe y Puerto Rico, en: Youngers C. A., Rosin E. (eds.), Drogas y democracia en America Latina: El impacto de la política de Estados Unidos, WOLA, Buenos Aires.

Rosen J. D., Zepeda Martínez R. (2014), La guerra contra las drogas en Colombia y México: estrategias fracasadas, "Ánfora", vol. 21, no. 37, disponible en: http://www.redalyc.org/ pdf/3578/357833888008.pdf, fecha de consulta: 02.05.2017.

Rosen J. D., Zepeda Martínez R. (2016), La guerra contra las drogas y la cooperación internacional: El caso de Colombia, "Revista CS", no. 18, enero-abril, disponible en: https:// www.icesi.edu.co/revistas/index.php/revista_cs/article/view/1848/2998, fecha de consulta: 02.05.2017.

Said Hung E. (ed.) (2013), Cooperación, comunicación y sociedad. Escenarios europeos $y$ latinoamericanos, Editorial Universidad del Norte, Barranquilla.

Sánchez Cobaleda A. (2011), La implicación de los EE.UU. en el Plan Colombia: Objetivos y resultados, Memoria final del Máster en Estudios Internacionales, Centro de Estudios Internacionales, Departamento de Derecho y Economía Internacionales, Universidad de Barcelona, Barcelona, disponible en: http://diposit.ub.edu/dspace/bitstream/2445/66913/1/ Memoria_Ana_Sanchez_Cobaleda.pdf, fecha de consulta: 02.05.2017.

Sol Gastaldi S. (2014), El acercamiento de Colombia a la OTAN: ¿Una estrategia pendular? Council on Hemispheric Affairs, 6 de noviembre, disponible en: http://www. coha.org/el-acercamiento-de-colombia-a-la-otan-una-estrategia-pendular/, fecha de consulta: 02.05.2017.

SRE (2015), Mecanismo de Diálogo y Concertación de Tuxtla (Mecanismo de Tuxtla), Secretaría de Relaciones Exteriores, disponible en: http://www.gob.mx/sre/acciones-y- 
programas/mecanismo-de-dialogo-y-concertacion-de-tuxtla-mecanismo-de-tuxtla, fecha de consulta: 02.05.2017.

Stavridis J. (2015), We know how to end drug violence in Central America, "Foreign Policy", 18 de marzo, disponible en: http://foreignpolicy.com/2015/03/18/we-know-how-to-enddrug-violence-in-central-america-colombia-drug-war/, fecha de consulta: 02.05.2017.

Súdarev V. (2013), México en búsqueda del liderazgo perdido en América Latina, „Iberoamérica”, no. 4, disponible en: http://www.ilaran.ru/pdf/2013/Iberoamerica/ IbA_2013_4/Sudarev.pdf, fecha de consulta: 02.05.2017.

The White House (2012), Declaraciones del Presidente Obama en la Cumbre de Empresarios de las Américas, 14 de abril, disponible en: https://obamawhitehouse.archives.gov/the-pressoffice/2012/04/14/declaraciones-del-presidente-obama-en-la-cumbre-de-empresarios-delas-am, fecha de consulta: 02.05.2017.

Tickner A. B. (2007), Intervención por invitación. Claves de la política colombiana y de sus debilidades principales, „Colombia Internacional”, no. 65, enero-junio, disponible en: https://colombiainternacional.uniandes.edu.co/view.php/93/view.php, fecha de consulta: 02.05.2017.

Tickner A. B. (2014), Colombia, the United States, and security cooperation by proxy, WOLA, 18 de marzo, disponible en: https://www.wola.org/analysis/colombia-the-unitedstates-and-security-cooperation-by-proxy/, fecha de consulta: 02.05.2017.

Tickner A. B., Morales M. (2015), Cooperación dependiente asociada. Relaciones estratégicas asimétricas entre Colombia e Estados Unidos, "Colombia Internacional", $\mathrm{n}^{\circ}$ 85, septiembrediciembre, disponible en: http://www.scielo.org.co/pdf/rci/n85/n85a07.pdf, fecha de consulta: 02.05.2017.

Tokatlian J. G. (1998), La cuarta descertificación, „El Tiempo”, 1 de marzo, disponible en: http://www.eltiempo.com/archivo/documento/MAM-767346, fecha de consulta: 02.05.2017.

UNODC (2016) Colombia. Monitoreo de territorios afectados por cultivos ilícitos 2015, United Nations Office on Drugs and Crime, julio, disponible en: www.unodc. org\%2Fdocuments\%2Fcrop-monitoring\%2FColombia\%2FMonitoreo_Cultivos ilicitos_2015.pdf\&usg=AFQjCNH5FL_g04jwniT0eP7roltjhEVR8Q\&sig2=yA6RH5SSARI T8wXu_xgvLQ, fecha de consulta: 02.05.2017.

Urrutia A. (2017), Efecto Trump hace declinar Iniciativa Mérida, "La Jornada”, 27 de enero, disponible en: http://www.jornada.unam.mx/2017/01/27/politica/006n1pol, fecha de consulta: 02.05.2017.

USCAP (2012), Plan de Acción de Cooperación en Seguridad Regional Colombia-Estados Unidos, U.S.-Colombia Action Plan on Regional Security Cooperation, Presidencia de la República, 15 de abril, disponible en: http://wsp.presidencia.gov.co/Prensa/2012/Abril/ Paginas/20120416_01.aspx, fecha de consulta: 02.05.2017.

Valdés G. (2013), Historia del Narcotráfico en México, Aguilar, México.

Velázquez Flores R., Prado Lallande J. P. (coord.) (2009), La Iniciativa Mérida: ¿Nuevo paradigma de cooperación entre México y Estados Unidos en seguridad? UNAM, UAP, SITESA, México.

Venegas J. M. (2011), Acuerdan los gobiernos de México y Colombia crear grupo bilateral de combate al narcotráfico, „La Jornada”, 7 de abril, disponible en: http://www.jornada.unam. $\mathrm{mx} / 2001 / 04 / 07 / 005 \mathrm{n} 1$ pol.html, fecha de consulta: 02.05.2017.
La cooperación de Colombia y México en la lucha contra el narcotráfico: Esperanzas y temores asociados con la implementación del modelo colombiano de la seguridad pública en México

Paweł Trefler Raúl Ruiz Canizales Benjamín Ortega Guerra 
VV. AA. (2004), Informe de la misión de observación sobre los efectos del Plan Colombia en los departamentos de Nariño y Putumayo, frontera colombo-ecuatoriana, noviembre.

Webinfomil (2016), A partir de hoy las Fuerzas Militares podrán bombardear y combatir a las bandas criminales, 5 de mayo, disponible en: http://www.webinfomil.com/2016/05/apartir-de-hoy-las-fuerzas-militares.html, fecha de consulta: 02.05.2017.

Youngers C. A., Rosin E. (eds.) (2005), Drogas y democracia en América Latina: El impacto de la política de Estados Unidos, WOLA, Buenos Aires. 